Universidad de Lima

Facultad de Comunicación

Carrera de Comunicación

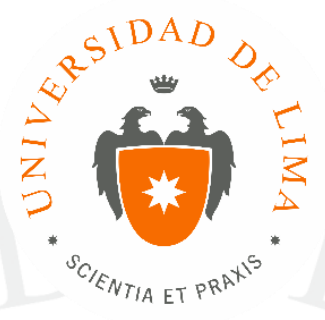

\title{
PROPUESTA ESTRATÉGICA DE COMUNICACIÓN PARA LA EMPRESA TEXTIL "KUYU ECOTEXTIL"
}

Trabajo de Suficiencia Profesional para optar el Título Profesional de Licenciado en Comunicación

\section{Marco Antonio Minaya Barrientos} Código 20080658

$$
\text { Lima - Perú }
$$

Martes 18 de septiembre del 2018 


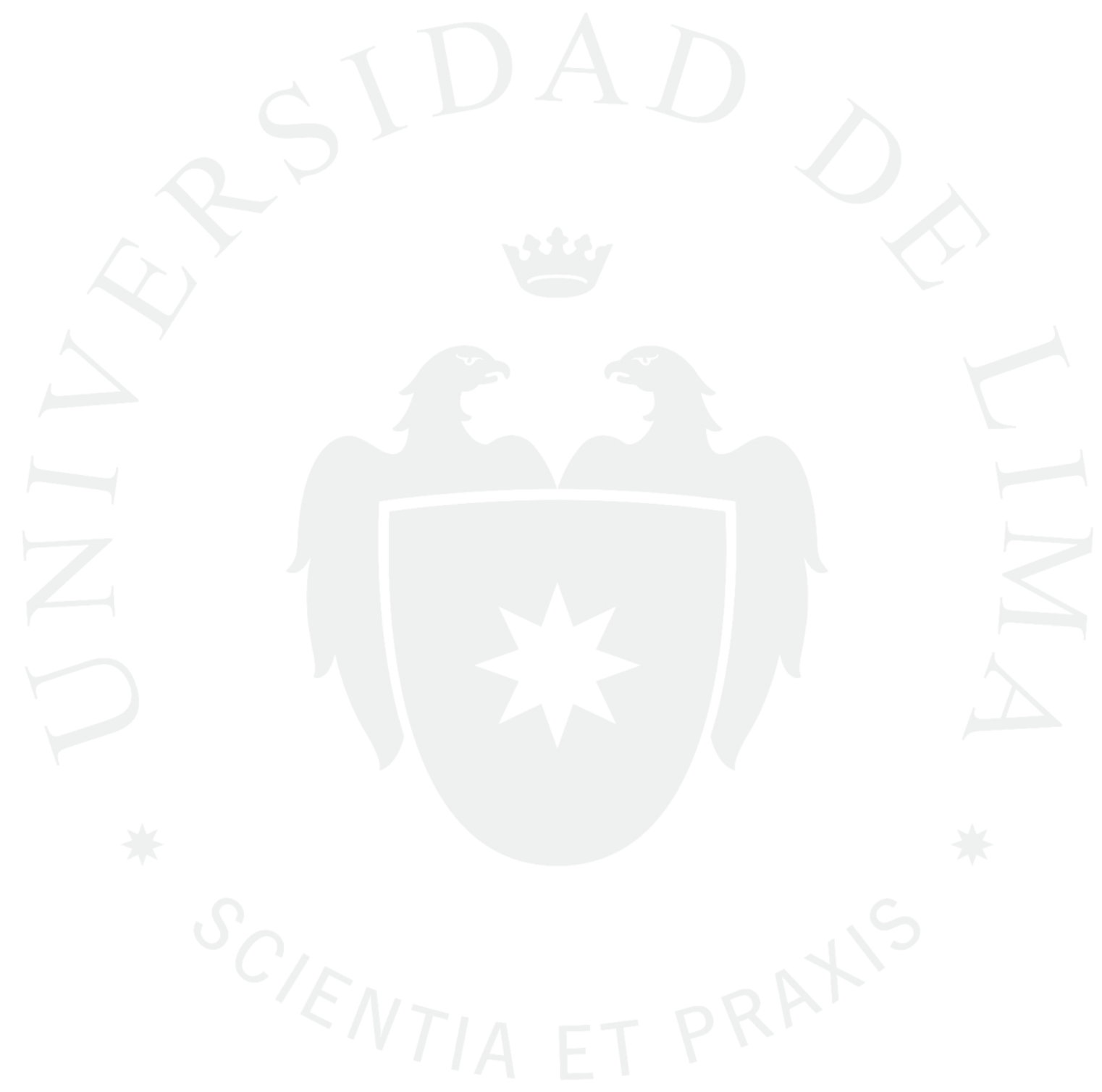




\section{PLAN ESTRATÉGICO DE COMUNUICACIÓN. CASO: EMPRESA TEXTIL "KUYU ECOTEXTIL"}




\section{ÍNDICE}

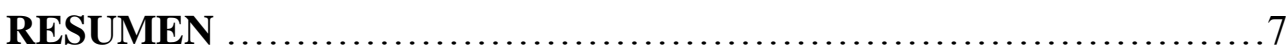

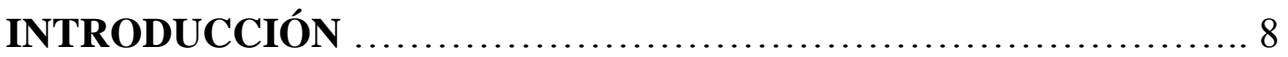

\section{ANÁLISIS DEL SECTOR Y CONTEXTO}

1.1 Moda e industria textil en el mundo 9

1.2 Moda e industria textil en el Perú ........................................ 12

1.3 Desarrollo sostenible y economía sustentable ....................... 15

1.4 Moda sostenible en el mundo y en el Perú (investigación de campo) ....16

\section{DIAGNÓSTICO DE LA COMUNICACIÓN}

2.1 Comunicación corporativa y el rol del director de comunicaciones (DirCom)..22

2.2 Análisis DAFO de comunicación .24

3. LINEAMIENTOS DE BUEN GOBIERNO CORPORATIVO, DESARROLLO SOSTENIBLE Y POLITICA DE COMUNICACIONES

3.1 Lineamientos de buen gobierno corporativa y desarrollo sostenible ........26

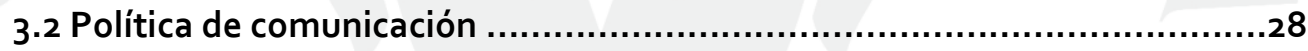

\section{MAPEO DE GRUPOS DE INTERES}

4.1 Importancia del mapeo de grupos de interés y la generación de valor compartido

4.2 Mapeo de grupos de interés

\section{ESTRUCTURA Y COMPETENCIAS DEL ÁREA DE COMUNICACIÓN}

5.1 Distinción de competencias 


\section{PLAN ESTRATÉGICO DE COMUNICACIÓN}

6.1 Primera prioridad estratégica de la organización .39

6.1.1 Primer objetivo de la comunicación

6.1.2 Eje estratégico

6.1.3 Estrategia

6.1.4 Público objetivo

6.1.5 Acciones tácticas

6.1.6 Indicadores

6.1.7 Presupuesto

6.2 Segunda prioridad estratégica de la organización .43

6.2.1 Segundo objetivo de la comunicación

6.2.2 Eje estratégico

6.2.3 Estrategia

6.2.4 Público objetivo

6.2.5 Acciones tácticas

6.2.6 Indicadores

6.2.7 Presupuesto

6.3 Tercera prioridad estratégica de la organización .45

6.3.1 Tercer objetivo de la comunicación

6.3.2 Eje estratégico

6.3.3 Estrategia

6.3.4 Público objetivo

6.3.5 Acciones tácticas

6.3.6 Indicadores

6.3.7 Presupuesto

6.4 Cuarta prioridad estratégica de la organización .48

6.4.1 Cuarto objetivo de la comunicación

6.4.2 Eje estratégico

6.4.3 Estrategia

6.4.4 Público objetivo 
6.4.5 Acciones tácticas

6.4.6 Indicadores

6.4.7 Presupuesto

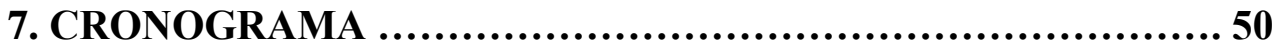

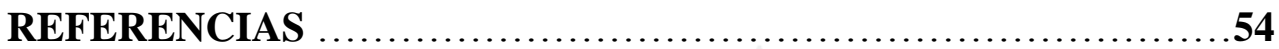

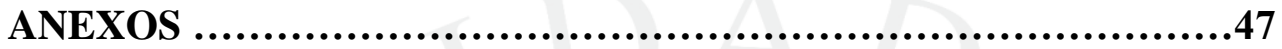




\section{RESUMEN}

Debido a las exigencias del mercado comercial en la actualidad, la empresa Confecciones S.A.C busca seguir expandiendo su línea comercial mediante sus productos de calidad y con el toque de peruanidad que lleva en su ADN organizacional. Sin embargo, enfrenta retos comunicacionales para seguir creciendo en los próximos años.

El presente plan de comunicación es una propuesta de comunicación corporativa que busca darle valor y reconocimiento a la marca con sus respectivos grupos de interés. Se trata de poner la gestión de la comunicación corporativa al servicio de la gente para que repercuta en todos los públicos. 


\section{INTRODUCCIÓN}

El presente plan estratégico de comunicación busca contribuir a la generación de valor y buen relacionamiento con los grupos de interés, con el fin de rentabilizar no solo capital financiero, sino también invertir de forma socialmente responsable, considerando los impactos ambientales que una empresa del sector textil, en muchas veces, ocasiona.

Este proyecto encuentra justificación en la estrategia, porque a raíz de allí viene toda la gestión. Como se podrá apreciar en el presente plan, el análisis que se realizó del sector, sumado al diagnóstico de la comunicación DAFO empleado para fines estratégicos, conllevan a pensar que los objetivos estratégicos que alcanza la organización se encentrarán estrechamente vinculado con esta propuesta de comunicación.

Se trata de pensar de forma transversal, respondiendo a los objetivos que la empresa tiene y estar acompañando al buen relacionamiento con cada grupo de interés, porque en una economía tan volátil, la comunicación debe ser como un escudo para salir al frente en este duro sector competitivo.

Por último, se ha desarrollado una serie de piezas gráficas que grafican la propuesta de comunicación señalada. 


\section{PARTE 1}

\section{ANÁLISIS DEL SECTOR / CONTEXTO}

\section{Moda e industria textil en el mundo}

No hay duda que la industria textil, rubro dedicado a la producción de fibras - natural o sintética-, hilados, telas y productos relacionados con la confección, elaboración, distribución y diseño de ropa, es un sector, cuyo eje comercial constituye una importante fuente de ingresos y generación de empleo para muchos países, sobre todo para aquellos que se encuentran en situación de desarrollo.

En este contexto, el sector privado ha sabido sacarle provecho a esta situación, realizando inversiones en países en las cuales se requiere de una mayor generación de empleo; en donde lo que a simple vista más importa es la exportación de prendas que compiten en el mercado por el bajo precio en las que son producidas, alcanzado una supuesta competitividad que en corto plazo les permitirá ser rentables.

Pese a los retos que enfrenta el sector en materia de comercio exterior y nivel de producción, existen casos como el de España en el que poco a poco va tomando forma las diversas reformas aplicadas al sector. Según la publicación del diario El Mundo, los patronales del sector textil firmaron en el mes de septiembre del presente año un nuevo convenio para el sector, que recoge, entre diversas líneas de acción, un alza salarial del $2 \%$ para este año y el próximo, y del 1,8 \% para 2020. Además, la nota destaca un aumento del $3 \%$ del salario mínimo intertextil, con el objetivo de acercarse a los 14 000 euros anuales al 2021 (Villaécija, 2018).

Por otra parte, dentro de los principales mercados de consumo de productos textiles e indumentarios, podemos mencionar a Europa Occidental, América del Norte y Japón. Cabe destacar el caso de China, país que es considerado como una potencia mundial en cuanto al comercio textil se refiere, teniendo como uno de sus pilares el nivel de exportación que desarrollan año tras año.

En el caso de Alemania, por ejemplo, juega un rol importante en el comercio exterior de textiles y prendas de vestir. Solo en el 2013, las importaciones textiles del país teutón llegaron a 36, 2 mil millones de euros y las exportaciones a 24, 0 millones de euros. Su 
textil técnico adquirió el $22 \%$ de la facturación de la industria textil y se encuentra globalizado, con un volumen de negocios de exportación de más del 60\% (Farré, 2015).

Francia, por su parte, ha tomado una postura comercial ligada al diseño e innovación de sus acabados, encontrándose en una situación de requerir mayor personal calificado y empoderado, capaz de adaptarse y asumir nuevos retos que les depara el contexto francés.

Según la International Team Consulting (2018), a pesar de dicha situación, Francia se mantiene como la tercera fuerza de la industria en Europa por detrás de Italia y Alemania, con un volumen de negocio del $12 \%$ y un $10 \%$ de ocupación. Cabe destacar que, para dicho país, la tecnología, el desarrollo sostenible y la moda son factores que explotan dentro de toda su cadena de valor, con el fin de seguir abriendo campo para ganar nuevos clientes; esto es lo que ellos llaman industria creativa.

En el caso de China, solo basta mirar las cifras para entender dicha situación. Por ejemplo, en la actualidad, Bolivia compra en China confecciones por US\$ 1900 millones de dólares y manufacturas por US\$ 1700 millones de dólares anuales. Si bien dicha industria textil es uno de los pilares de la economía boliviana en cuanto a producción, cerca del $22 \%$ del total de las importaciones textiles del país vecino provinieron de China durante el 2017. En ese sentido, según cifras oficiales del Instituto Nacional de Estadística de Bolivia (INE), "las prendas textiles, provenientes del continente asiático se comercializan en el país a un precio de $15 \%$ menos que los del mercado", informó Fashion Network, portal de noticias relacionadas al mundo de la moda. Sin duda alguna, esto representa un malestar para las marcas bolivianas, dado que, ante el bajo costo de las prendas chinas y su crecimiento comercial en el país, ha provocado la quiebra de algunas firmas locales, debido a su imposibilidad de competir, lo cual, como efecto secundario, genera desempleo e informalidad para aquellos productores y distribuidores quienes quieran seguir operando en el sector (PerúRetail, 2018).

Siguiendo esa línea, de acuerdo al último informe de la Cámara Industrial Argentina de la Indumentaria (CIAI), basado en los principales países de origen de las importaciones de prendas de vestir en el año anterior, publicado en enero del presente año, el gigante asiático se confirmó como el país que más exporta prendas de vestir hacia Argentina en 
los primeros 11 meses del 2017, con una participación del 70 \% sobre el volumen del total importado (Mares, 2018). En efecto, al igual que el caso de Bolivia, existe una clara presencia del gigante asiático en cuanto al nivel de exportación textil.

Del mismo modo, dicho informe señala que los tipos de prendas que Argentina compra a China son los abrigos, suéteres, prendas de sastrería y pantalones de algodón; todas bajo la categoría "Made in China". Según los datos de la CIAI, las prendas que ingresan a Argentina son en su mayoría piezas fabricadas en fibras sintéticas o impregnadas. De esto último se desprende el hecho que dicho material sintético cause un impacto grave al medio ambiente.

Estas fibras sintéticas se obtienen por diversos productos derivados del petróleo como el poliéster, el nylon o spandex; siendo esta fibra en su mayoría enteramente química. Si bien estos textiles son económicos, durables y resistentes, no deja de generar un impacto negativo al medio ambiente (Lafayette, 2017). Tanto China como Bangladesh, Vietnam, India, entre otros son países en la actualidad los que destacan por el alto nivel de producción y mano de obra barata desarrollado en dichos territorios.

En el caso de Bangladesh, siempre representa un punto de inflexión en cuanto a la industria textil se refiere. Y no solo por lo anteriormente comentado, sino por lo suscitado en la mañana del 24 de abril del 2013: la estructura de la Rana Plaza se derrumbó en cuestión de segundos, acabando con la vida de al menos 300 personas y causó unos 1000 heridos. Dicho escenario fue en un edificio de 8 plantas en Savar, a las afueras de Dhaka, en el que unos 5000 trabajadores, sobre todo mujeres, cosían para 5 contratistas locales que abastecían a más de 30 marcas internacionales (Olazábal, 2018).

Hoy por hoy, Bangladesh es considerado como un país en el que se pueden producir prendas de ropa a bajo costo; en el que las condiciones de trabajo no son las más adecuadas. Otro ejemplo similar al anterior tuvo origen en Camboya, país donde la mano de obra del sector textil es sumamente barata y donde justamente las grandes marcas americanas y europeas producen sus prendas. El salario es sólo un $21 \%$ de lo que Asia Floor Wage, socia de la campaña de "Ropa Limpia", calcula que es el salario digno de ese país (Campaña Ropa Limpia, 2013).

La mayor parte de las personas que trabajan en el sector textil en Camboya son mujeres que viajan a la ciudad desde áreas rurales con la esperanza de que la industria textil les 
proporcione suficientes ingresos como para mantenerse a sí mismas y a sus familias. Sin embargo, a menudo la realidad es muy distinta. Sólo el 5\% de las fábricas de Camboya no tienen un exceso de horas extraordinarias. Las semanas laborales extremadamente largas llegan hasta las 70 horas o más.

En resumen, la industria textil en el mundo mueve mucho dinero. Las empresas que derivan todos los asuntos de importación siempre se van a ver forzados, por temas económicos, por abaratar costos, sin pensar necesariamente en la repercusión que tiene enfoque meramente comercial en el medio ambiente. Países como Bangladés o Camboya son solo ejemplos representativos de lo que sucede en el sector. Mientras que existen zonas como Europa Occidental, América del Norte y Japón, quienes en muchos casos desarrollan procesos prácticos de agilizar el comercio y manufacturación, también existe una contra parte como Camboya que se ve forzada a estar sujeta a jornadas laborales arduas y a un peligro inminente que no solo afecta al medio ambiente, sino a la integridad física y emocional de quienes laboran en dicho sector.

\section{Moda e industria textil en el Perú}

En el caso de nuestro país, la industria textil en los últimos años ha venido convirtiéndose en un importante sector industrial, que mueve considerables cifras de facturación y generación de empleo en el Perú.

Cabe mencionar que podemos distinguir dos grandes ámbitos dentro de la cadena de valor que constituye la actividad manufacturera textil: la industria textil en concreto y la industria de la confección. La primera abarca desde la etapa inicial del desmonte del algodón o algún tipo de materia prima hasta la propia elaboración de las telas acabadas, incluyendo, a su vez, a las actividades del hilado, tejido y teñido acabado. Mientras que el segundo ámbito comprende todas las actividades vinculadas a la confección de prendas de vestir (Herrera Gómez, Lazo Damián, Mollo Bustamante y Vera Melgar, 2010). No cabe duda que la calidad de las confecciones elaboradas en base a la fibra de alpaca y su fino algodón destacan a nivel tanto nacional como internacional.

Según el portal Perú Info (2017), portal oficial de la Marca Perú, en relación a sus exportaciones, a pesar de haber perdido un poco de terreno en el año 2016, las 
exportaciones de la industria textil y confecciones se recuperaron durante el 2017, creciendo un $6,1 \%$ y generando un total de US\$ 1,271 millones. Cabe precisar que las ventas en este sector se distribuyeron a 119 mercados en el 2017, doce más con respecto al 2016. Mientras tanto, los principales mercados de destino de exportaciones textiles son Estados Unidos (US\$ 628 millones), Ecuador (US\$ 62 millones), Chile (US\$ 68 millones), Brasil (US\$ 57 millones) y Colombia (US\$ 57 millones).

Como ejemplo, podemos mencionar que las exportaciones peruanas de confecciones hacia los Estados Unidos registraron una tasa de crecimiento promedio anual del 4,3\% en los últimos tres años, informó el Centro de Comercio Exterior (CCEX) de la Cámara de Comercio de Lima (CCL). Este importante mercado concentra el $69 \%$ del total que se exporta al mundo, seguido de Brasil que apenas alcanza el $5 \%$ con US\$ 41 millones (El Comercio, 2018).

Según el Comité Textil de la Sociedad Nacional de Industria (SNI), la cadena del sector textil-confecciones representa el $1.9 \%$ del PBI y el $10 \%$ de la manufactura. Se estima que alrededor de 2.8 millones de personas dependen directa e indirectamente de dicha cadena productiva. Solo para destacar del nivel de exportación que desarrolla nuestro país, según cifras del Ministerio de Comercio Exterior y Turismo (Mincetur), las exportaciones textiles de alpaca crecieron en $48,8 \%$ en el primer semestre del presente año, alcanzando los US\$ 103 millones. En este periodo, las prendas de vestir crecieron en un 22,1\% y llegaron a los US\$ 12 millones, siendo los Estados Unidos, Chile, Canadá, Australia y Alemania los principales mercados de destino (Bardales, 2018).

Según declaraciones tomadas del diario La República, el ministro de Comercio Exterior, Rogers Valencia, expresó que se trata de una actividad de la que forma parte más de 120 mil familias peruanas. Señaló que el Perú sale a contribuir a la economía mundial con un producto de alta calidad, singular y con nombre propio. Asimismo, estimó que la exportación de los productos textiles a base de alpaca podría crecer más del $25 \%$ al término del 2018 (Lozano, 2018). Este aspecto es importante a destacar dentro del presente trabajo, dado que nos podemos dar cuenta que el grado de repercusión nacional e internacional que tiene el Perú en relación a su nivel de exportación es descollante. 
De dicha nota se puede recoger también las declaraciones del director de exportaciones de Promperú, Luis Torres, quien detalló que, en materia de comercio digital, se está buscando implementar dicho canal como una opción de venta para todas las empresas del sector. "Pensamos que al 2021 el programa de e-commerce deberá generar más de US\$ 1. 000 millones en exportaciones" acotó. De esta forma, se busca posicionar a las marcas Perú a nivel internacional, lo cual se convierte en una insignia para la calidad del producto peruano. Podemos apreciar que desde el propio Estado se fomenta el desarrollo de nuevas estrategias vinculados al comercio digital para conseguir mayor apertura hacia mercados aún no explorados.

Del mismo modo, según informó Promperú, mientras que Estados Unidos aumentó, entre enero y abril de este año, sus importaciones de prendas de vestir al mundo en 2.4 $\%$, su demanda por prendas de vestir peruanas creció un $6 \%$ en el mismo periodo, más de los obtenido por China, Bangladesh, Vietnam y México. De esta forma, el Perú se posiciona como uno de los principales proveedores del país norteamericano ubicados en el top tep. De acuerdo a esta entidad gubernamental, nuestro país ocupó el quinto lugar como proveedor de suéteres de algodón a los Estados Unidos, con un crecimiento del $9.2 \%$ (Medina, 2018).

Según el portal de Promperú, se espera que las proyecciones para el 2018 sean bastante optimistas, sobre todo por el impulso de alta demanda de polos de algodón. "Para el 2018, las proyecciones para este sector son favorables, pues se espera una mayor demanda de nuestros distintos mercados, que permitirá cerrar este año con una recuperación del 4 \% respecto al 2017”, afirmó el ex ministro peruano de Producción, Pedro Olaechea (Perú Info, 2017).

En resumen, la postura del Estado es clara en cuanto a que las empresas puedan acompañar al Estado en relación a promover más el comercio electrónico para expandir mercado. Teniendo en cuenta el factor de calidad y e innovación en la que destacan los productos que se elaboran en nuestro país, esto convierte al Perú en su ventaja competitiva en el mercado, junto a la calidad de las fibras que están consideradas como de las mejores del mundo. Esto ha permitido a la industria textil y de confecciones presentar una tendencia creciente en su producción. 


\section{Desarrollo sostenible y economía sustentable}

Teniendo en cuenta el gran impacto que ocasiona la industria textil en el mundo y en el Perú, es preciso determinar el por qué la empresa Confecciones S.A.C. apuesta por un modelo más sustentable, que priorice el cuidado del medio ambiente dentro de su cadena de valor.

Debemos remitirnos, entonces, a la comisión de las Naciones Unidas en el año 1987, haciendo público su informe titulado "Nuestro futuro común ("Our common future”, en su versión en inglés), conocido también como "Informe Brundtland" del cual se desprende el concepto de desarrollo sostenible:

"Está en manos de la humanidad asegurar que el desarrollo sea sostenible, es decir, asegurar que satisfaga las necesidades del presente sin comprometer la capacidad de las futuras generaciones para satisfacer las propias" (citado en Gómez Gutiérrez, 2014).

¿Por qué esto es vinculante con una empresa de un sector como el textil?

Se ha visto a lo largo del análisis del sector que dicho sector emplea grandes proporciones de agua en la elaboración de una prenda. Según advirtió un informe de la ONU, de continuar el actual consumo de agua, el mundo enfrentará una severa escasez del recurso hídrico al 2030, lo que podría desatar conflictos entre diversos sectores económicos e incluso entre regiones y países. Dicho informe precisó que en el ritmo en que venimos consumiendo el recurso hídrico, al 2030 faltará un $40 \%$ del agua que necesitaría el planeta para subsistir y mantener sus actividades productivas (Blanco, 2015).

De no poder continuar con este ritmo, no existiría una industria textil, perjudicando gravemente al sector y obligando al empleo de otro tipo de recursos para su subsistencia. Es por eso que para una empresa como Confecciones S.A.C. Es por eso que para dicha empresa resulta clave introducirse en un enfoque de desarrollo sostenible, que por condiciones del sector en donde opera, este basado en un modelo de economía sustentable. Entiéndase esto ultimo como una ruta más confiable en búsqueda de la prosperidad responsable del negocio, basado en principios como la ética en los negocios, comercio justo, derechos humanos, respeto por las normativas 
ambientales, protección del medio ambiente, inversión responsable y una búsqueda incesante de mejoras en la cadena de valor (Chouinard, Ellison y Ridgeway, 2011).

Frente a este escenario es que la empresa Confecciones S.A.C debe desarrollar su camino hacia la rentabilidad y bienestar económico, social y ambiental de su negocio.

\section{Moda sostenible en el mundo y en el Perú (investigación de campo)}

Lo anteriormente mencionado nos permite conocer a grandes rasgos en qué situación se encuentra la moda textil a nivel internacional y local, enfatizando el nivel de exportación que tiene el Perú y su destacado valor, cuyo eje radica en la calidad de sus confecciones textiles y acabados. Sin embargo, la industria textil y de la moda en general es la segunda más contaminante del planeta, después de la industria del petróleo. ¿De qué forma se traduce este impacto negativo al medio ambiente? La respuesta recae en el empleo rápido de prendas, o como también denominado "fast fashion", que hace que las prendas duren menos, está haciendo daños irreparables en nuestro planeta.

Para ejemplificar dicho escenario, en los últimos años se ha descubierto que las microfibras sintéticas que se desprenden al lavar nuestra ropa están contaminando el agua de los océanos. Según un estudio realizado por la Universidad de California, se puede analizar cómo se desprenden 1,7 gramos de microfibras en cada lavado. Estas microfibras sintéticas son muy peligrosas, ya que contienen sustancias toxicas (Fernández, s.f.) Esta responsabilidad recae en manos de la industria textil, que en muchos casos elaboran las prendas con materiales sintéticos, ocasionando daños nocivos al medio ambiente.

Solo por mencionar algunos problemas que enfrenta la industria textil: aguas residuales que genera, carga química producto de la elaboración de prendas, consumo de agua y energía, malos olores, residuos sólidos, ruidos, generación de emisiones atmosféricas, explotación de mano de obra barata e infantil. Todo esto se encuentra en lo que muchos especialistas y referentes de la industria textil llaman como fast fashion.

Según el ESME® Escuela de moda (s.f.), el fast fashion es un término empleado por minoristas de la moda para trasladar las propuestas de las grandes casas de diseño, 
desde las pasarelas a sus tiendas para capturar alguna tendencia lo más rápido posible. Se trata de una estrategia para recrear las tendencias presentadas en el Fashion Week, manufacturando prendas de forma acelerada y a un bajo costo para que los consumidores promedio tengamos la oportunidad de adquirir prendas con un estilo a un precio accesible. Entre las marcas más destacadas que trabajan bajo este concepto de fast fashion tenemos a Zara, Topshop, C\&A, Primark, Asos, Forever 21, Mango y H\&M.

En el documento de la Comisión Económica de las Naciones Unidas para Europa (UNECE), se advierte que la industria de la moda, desde la lógica del fast fashion, es responsable de producir el $20 \%$ de las aguas residuales mundiales y el $10 \%$ de las emisiones mundiales de carbono, más que las emisiones de todos los vuelos internacionales y el envío marítimo, combinados. La cadena de valor que forma parte tanto la confección y distribución textil está impactando de una forma desproporcionada el medio ambiente. Solo la producción de algodón es responsable del $24 \%$ de los insecticidas y del $11 \%$ de los plaguicidas, a pesar de que solo utiliza el $3 \%$ de la tierra cultivable del mundo (Catorce6, 2018).

En resumen, el fast fashion se trata de una tendencia de colecciones diseñadas y fabricadas que tienen una alta rotación en las tiendas que genera grandes impactos tanto sociales como medio ambientales. Según el blog de Ester Xicota, co-fundadora de la Asociación de Moda Sostenible del Perú (AMSP), el negocio global de las marcas fast fashion en los últimos años, ha visto un crecimiento de las ventas del $15 \%$, mucho más alto que el promedio de la industria. Además, sus márgenes de beneficios (10 \%) son más altos que de las grandes marcas globales de tecnologías de la información (Xicota, 2018).

Considerando estos aspectos negativos, en los últimos años se viene desarrollando diversas alternativas para contrarrestar dicha situación, implementando dentro de la cadena de valor alternativas a las formas de producción convencionales para poder lograr productos textiles menos contaminantes. Es así que en este escenario surge la moda sostenible.

Partiendo de la definición de la Asociación de Moda Sostenible del Perú, se entiende a la moda sostenible como "aquellos productos rentables como prendas de vestir, calzado, 
joyas, carteras y accesorios que buscan crear armonía productiva con el ambiente y las personas en todo su ciclo de vida". Según dicha asociación, esto se puede manifestar en distintas líneas de acción como por ejemplo moda ética, aquella que respeta los derechos humanos y laborales; la moda ecológica, que busca el cuidado del medio ambiente y la moda étnica, que revaloriza y promueve las técnicas ancestrales.

En este contexto, la moda sostenible está evolucionando y aparece como una respuesta y contraparte al consumo subliminal y desmesurado: a la explotación, contaminación de recursos naturales, la injusticia laboral y social. En ese sentido, dicha tendencia lucha contra estos problemas, insertando reducciones de emisiones y contaminación en los procesos de producción, reducción y control de extracción de las materias primas, comercio justo, condiciones laborales óptimas para los trabajadores y la comunicación de toda la historia que está detrás de una prenda.

En una entrevista realizada a Ester Xicota, co-fundadora de la Asociación de Moda Sostenible del Perú (AMSP) (Ver entrevista completa en anexo), realizada por mi persona para la Revista Stakeholders, medio en donde trabajo, manifestó que de las 253 empresas que se inscribieron al primer directorio de moda sostenible en el Perú, la AMSP filtró hasta quedarse con 75 organizaciones. De estas, el $65 \%$ eran empresas y el $17 \%$ empresas sociales. El $80 \%$ de las organizaciones radica en Lima.

\begin{tabular}{|c|c|c|}
\hline Diseño & $81 \%$ & valor, se puede apreciar que estas trabajan en \\
\hline Confección & $75 \%$ & $\begin{array}{l}\text { sus propios diseños (81\%), confeccionan (75 } \\
\%) \text { y venden al cliente final ( } 83 \%) \text {. Muchas de }\end{array}$ \\
\hline $\begin{array}{l}\text { Venta al } \\
\text { cliente final }\end{array}$ & $83 \%$ & $\begin{array}{l}\text { estas organizaciones confeccionan telas (55\%) } \\
\text { y un } 60 \% \text { elabora accesorios }{ }^{1} \text {. }\end{array}$ \\
\hline $\begin{array}{l}\text { Tejido y/o } \\
\text { confección } \\
\text { de telas }\end{array}$ & $55 \%$ & \\
\hline Accesorios & $60 \%$ & \\
\hline
\end{tabular}

\footnotetext{
${ }^{1}$ Datos tomados del Primer Directorio de Moda Sostenible del Perú
} 
En relación a puntos clave de la moda

- Producción

local

sostenible, las acciones que más destacan de las organizaciones peruanas son la producción local $(79 \%)$, trabajo artesanal (79\%), trabajo con materiales naturales $(73 \%)$ y con un fuerte componente de inclusión social $(69 \%)^{2}$

\section{Trabajo} artesanal

Materiales naturales

Inclusión social

Por último, en dicha entrevista, Xicota también destacó dos puntos importantes, vinculados al consumidor peruano y al rol que la gestión de la cadena de valor. Respecto al primer punto enfatizó que el consumidor peruano, como en general los consumidores de moda de todo el mundo, es ajeno aún a la magnitud de los impactos que tienen las prendas que compran. Esto evidencia una oportunidad para que más empresas apuesten por este enfoque que les permita diferenciarse del mercado. Mientras que en relación a la gestión de la cadena de valor (supply chain management) fue tajante al expresar que resulta esencial en el camino hacia una moda más sostenible.

En la misma línea que argumenta Xicota, cuando se hizo una entrevista a Pool Rousell Ccanto, docente de la Maestría en Supply Chain Management de la Universidad Esan, enfatizó que el gran problema del sector es la informalidad con la que trabajan las empresas que participan en la cadena, esto va desde los agricultores del algodón hasta los puntos de venta.

Del mismo modo, comentó que otro de los problemas es la mano de obra calificado, ya que únicamente se busca obreros que hagan procesos de corte, costura o pegado de botones, pero se invierte poco en creación de diseños o en generar tendencias. Se trata de revalorizar el rol que cumple el trabajador textil empoderándolo más en estos temas, ya que es el responsable del proceso productivo, que va desde el diseño de la

\footnotetext{
${ }^{2}$ Datos tomados del Primer Directorio de Moda Sostenible del Perú
} 
prenda hasta la distribución, pasando por la selección de materiales a emplear, con el fin de satisfacer la necesidad de los consumidores.

En otra entrevista realizada por mi persona para el medio en donde trabajo, conversé con Ornella Paz, cofundadora también de la AMSP, quien aseveró que, en nuestro país, el $39 \%$ de personas dicen ser leales a una marca, mientras que el $61 \%$ restante está dispuesto a cambiarla, debido a que como no se encuentra la marca adecuada están dispuestos a probar nuevas opciones, y para ello las marcas deben estar preparadas para generar propuestas interesantes que cubran las expectativas de sus consumidores y además, les brinden un valor agregado como la sostenibilidad y la innovación, intangibles muy valorados por ellos.

"No en vano hoy en día existen rankings, certificaciones y hasta premios que califican a las empresas y marcas por sus indicadores como la confiabilidad, transparencia, responsabilidad social empresarial, innovación, entre otros. Esto nos brinda una idea muy clara de cuál es la demanda", explicó Paz.

Del mismo modo, agregó que la decisión de una marca o empresa del sector textil de apostar por la sostenibilidad, implementar procesos limpios en su cadena de valor que contribuyan al cuidado del medio ambiente, reducir el uso de agua y de productos químicos en sus diferentes procesos, brindar salario justo, no ejercer el uso de la mano de obra infantil, respetar por los derechos laborales y humanos, generar comercio justo, entre otros aspectos, definitivamente lo diferenciará del resto de marcas comerciales.

En resumen, se trata de concientizar, educar y comunicar al consumidor todo lo que está oculto en cada proceso del ciclo de vida de la prenda.

En conclusión, existen puntos claves que a lo largo de este análisis del sector se ha realizado. Si pretendemos establecer un plan de comunicación integral y estratégico, imposible soslayar estos factores que determinarán el patrón o lineamiento general de dicha propuesta comunicacional.

En ese sentido, esta estrategia comunicacional estará en función de generar valor y buen relacionamiento con los respectivos grupos de interés que la empresa desarrolle. Está claro que el contexto de la industria textil enfrenta retos como el negativo impacto ambiental y explotación laboral que genera en muchos casos. Frente a ello, tomando en 
consideración dichos apuntes, el plan aborda una serie de líneas de acción en función tres ejes estratégicos: cultura organización y gestión del cambio, desarrollo sostenible e innovación, con el fin de no solo posicionar a la corporación con un nuevo nombre y marca, sino también el contribuir con los objetivos estratégicos que persigue la organización.

Aunque resulte una obviedad, este plan de comunicación está basada en seguir los objetivos que establece la organización para convertirse en los próximos 10 años en una de las empresas textiles de mayor éxito en el Perú, considerando el enfoque ambiental como uno de sus valores más prioritarios dentro de su sector. 


\section{PARTE 2}

\section{DIAGNÓSTICO DE LA COMUNICACIÓN}

\section{Comunicación corporativa y el rol del director de comunicaciones (DirCom)}

Para fines del presente plan de comunicaciones, es necesario situarnos en el contexto que envuelve a la comunicación corporativa y el rol que tiene el director de comunicaciones (DirCom) en este escenario.

En ese sentido, según el Dr. Paul Capriotti, la expresión "comunicación corporativa" ha sido utilizada de muchas maneras, y principalmente para denominar la comunicación de carácter institucional de una empresa u organización. Para el especialista, tiene una significación mucho más amplia y profunda, dado que llama a la comunicación corporativa como la totalidad de los recursos de comunicación de los que dispone una organización para llegar efectivamente a sus públicos. Es decir, la comunicación corporativa de una entidad es todo lo que la empresa dice sobre si misma. En este punto, destaca que el comunicar implica el transmitir a los públicos, de forma creativa y diferenciada, los mensajes creados de forma voluntaria, directa y organizada, acerca de todas las actividades que la organización realiza. (Capriotti, 1999)

Lo que expresa Capriotti, desde el punto de vista más práctico, no deja de tener relevancia. Sin embargo, cabe precisar que la comunicación, para fines que persigue el presente plan de comunicaciones, debe también considerar a dicha gestión como un proceso, en el que se desprende diversas acciones. Joan Costa, considerado como uno de los mayores referentes en el ámbito de la comunicación corporativa, explica al detalle lo concerniente al proceso.

"La comunicación en tanto que un modo de acción, es un proceso, y el mecanismo que lo sustenta en el espacio-tiempo es la interacción; esta se basa en la retroacción (acción en retorno o feed back). Los términos que describen los procesos de comunicación empresarial giran claramente alrededor del principio de acción y sus modalidades: interacción, retroacción, proacción, transacción, teleacción”. (Costa, 2012, pág. 32)

Es en este escenario que la figura del Dircom toma relevancia. Para Joan Costa, si bien el Dircom integra en sus conocimientos y habilidades los aspectos básicos del 
management como son la economía y las prácticas directivas - ayudado obviamente con el dominio de los idiomas y las nuevas tecnologías de información y comunicación, herramientas indispensables-, en realidad, lo que constituye su originalidad y su especificidad como DirCom o estratega corporativo es el conjunto de los nuevos conocimientos en materias cruciales integradas al management, como las comunicaciones, la información y la estrategia. Otros conocimientos complementarios, como la teoría de la organización, el marketing y la investigación estratégica global, completan los campos que el DirCom atraviesa y en los que aplica la estrategia, la planificación y la gestión. (Costa, 2012, pág. 29)

Frente a un escenario como el de la industria textil, nuestro DirCom debe estar preparado para toda circunstancia, y abordar todo tipo de situación ya sea del día a día o algún hecho repentino que suceda y que pueda provocar una posible crisis. Además, es el responsable de dirigir la estrategia en función de los objetivos de la organización, con el fin de que la estrategia de comunicación sea eficientemente alineada. Se trata de pensar y actuar de forma estratégica.

¿Qué quiere decir esto? "Pues consiste en detenernos a pensar qué queremos transmitir, a quiénes, a través de qué medios y/o acciones, cuándo, dónde, con qué inversión (energética, intelectual, temporal, psicológica, técnica y financiera), y con qué resultados. Cuando hablo de transmitir no me refiero a lo que hacen algunas organizaciones que simplemente se limitan a informar (unidireccionalmente y sin haber trabajado lo que se quiere difundir), sino más bien a comunicar (bidireccionalmente con un mensaje trabajado en función de las variables antes enumeradas). Por ende, es muy importante que todas las comunicaciones que la organización difunda hacia sus públicos internos (colaboradores) y externos estén planificadas en conjunto de manera sinérgica, para no comunicar diferentes mensajes hacia fuera y hacia dentro de la organización” (Rosenthal, 2002).

Bajo este panorama, se tendrá en cuenta dichos puntos para la presentación del plan de comunicación para el presente caso. En ese sentido, habiendo desarrollado un pequeño marco contextual acerca del papel que tiene la comunicación corporativa y el rol que debe asumir el DirCom en este escenario, se procede a realizar un análisis DAFO de comunicación, permitiendo ver todas las fortalezas, debilidades amenazas y oportunidades que empresa Confecciones S.A.C en materia de comunicación. 


\section{Análisis DAFO de comunicación}

Para entender la situación comunicativa actual de Confecciones S.A.C, se ha elaborado un breve análisis DAFO en el que se ha intentado plasmar aquellos puntos positivos y negativos que tiene la empresa, así como sus amenazas y oportunidades a tener en la propuesta del plan estratégico de comunicación. Cabe mencionar que estos puntos, en la medida de lo posible, están vinculados a aspectos de la gestión de comunicación, y algunos aspectos vinculados al giro del negocio en las cuales la adecuada gestión de la comunicación puede contribuir a los objetivos organizacionales de la empresa.

\begin{tabular}{|c|c|}
\hline \multicolumn{2}{|c|}{ ANÁLISIS DAFO DE COMUNICACIÓN DE CONFECCIONES S.A.C } \\
\hline FORTALEZAS & DEBILIDADES \\
\hline $\begin{array}{l}\text { "Confecciones S.A.C" cuenta con una } \\
\text { trayectoria de más de } 20 \text { años operando } \\
\text { como proveedor. Es decir, tienen } \\
\text { conocimiento y experiencia en el sector. }\end{array}$ & $\begin{array}{l}\text { No cuentan con un área de } \\
\text { comunicaciones. }\end{array}$ \\
\hline $\begin{array}{l}\text { El producto con el que trabajan está hecho } \\
\text { de material peruano. Factor de } \\
\text { peruanidad. }\end{array}$ & $\begin{array}{l}\text { El nombre "Confecciones S.A.C" es poco } \\
\text { beneficioso para expandir su mercado. }\end{array}$ \\
\hline $\begin{array}{l}\text { Presupuesto de } 15 \text { millones de soles para } \\
\text { los tres primeros años para asumir costos } \\
\text { ligados a la comunicación. }\end{array}$ & $\begin{array}{l}\text { Existencia de una cultura corporativa } \\
\text { débil que perjudica al colaborador, dados } \\
\text { los altos índices de rotación. }\end{array}$ \\
\hline $\begin{array}{l}\text { Disponibilidad local para trabajar } \\
\text { directamente con los proveedores } \\
\text { ubicados en Arequipa y Ayacucho. }\end{array}$ & $\begin{array}{l}\text { Los canales de comunicación no son los } \\
\text { más adecuados. }\end{array}$ \\
\hline AMENAZAS & OPORTUNIDADES \\
\hline Alto nivel de informalidad que & El mercado textil está creciendo \\
\hline
\end{tabular}




\begin{tabular}{|l|l|}
\hline la industria textil. & internacionalmente. \\
\hline $\begin{array}{l}\text { Los socios están evaluando migrar a otros } \\
\text { a mercados del Asia, donde la mano de } \\
\text { obra es más barata. }\end{array}$ & $\begin{array}{l}\text { Apuesta por el comercio electrónico con } \\
\text { tiendas virtuales de vanguardia. }\end{array}$ \\
\hline $\begin{array}{l}\text { Tendencia del fast fashion en el sector } \\
\text { textil tanto a nivel internacional como } \\
\text { local. }\end{array}$ & $\begin{array}{l}\text { implica un producto eco amigable a } \\
\text { nuedta diferenciarse de su competencia, } \\
\text { abracando la tendencia de moda } \\
\text { sostenible. }\end{array}$ \\
\hline $\begin{array}{l}\text { Competencia agresiva que existe en el } \\
\text { sector textil. }\end{array}$ & $\begin{array}{l}\text { Espacio para concientizar a los } \\
\text { proveedores sobre la importancia de } \\
\text { gestionar en la empresa una cadena de } \\
\text { valor responsable. }\end{array}$ \\
\hline
\end{tabular}




\section{PARTE 3}

\section{LINEAMIENTOS DE BUEN GOBIERNO CORPORATIVO, DESARROLLO SOSTENIBLE Y COMUNICACIÓN}

\section{Lineamientos de buen gobierno corporativa y desarrollo sostenible}

En la actualidad, las empresas buscan proteger los bienes tangibles e intangibles relacionados a su giro de negocio. Sobre todo, en situaciones en las cuales son expuestas a posibles riesgos o crisis que como toda empresa se vea sujeta a afrontar por las distintas circunstancias del día a día. Más aún si se tiene en cuenta la agresiva competencia, en muchos casos desleal competencia, que exista en su sector.

En este contexto, la industria textil no es ajena a dicha realidad. Pensar solo en los riesgos que puede enfrentar la empresa Confecciones S.A.C hace suponer que debe estar preparado para enfrentar todo tipo de problemas.

¿Por qué es importante establecer lineamientos de buen gobierno corporativo y sostenibilidad y cuál es la relación que existe con un plan estratégico de comunicación?

Para responder a dicha pregunta y argumentar una clara justificación al respecto, es pertinente citar una definición acerca de lo que entendemos por gobierno corporativo.

Por consiguiente, de acuerdo a la Organización para la Cooperación y el Desarrollo Económico - OCDE:

El gobierno corporativo es el sistema por el cual las sociedades son dirigidas y controladas. La estructura del gobierno corporativo especifica la distribución de los derechos y responsabilidades entre los diferentes participantes de la sociedad, tales como el directorio, los gerentes, accionistas y otros agentes económicos que mantengan algún interés en la empresa. El gobierno corporativo también provee la estructura a través de la cual se establecen los objetivos de la empresa, los medios para alcanzar estos objetivos, así como la forma para alcanzar estos objetivos, así como la forma de hacer un seguimiento a su desempeño. (citado en Flores y Rozas, 2008). 
De acuerdo a la definición citada, podemos inferir que este sistema permite darle una uniformidad y estructura clara en relación a los objetivos que persigue la organización.

En ese sentido, respondiendo a la pregunta planteada, partiendo del hecho de darle un enfoque estratégico a la gestión de la comunicación a nivel organizacional, y entendiendo que los objetivos trazados por la empresa no deben desvincularse de los objetivos de comunicación propuestos, es necesario determinar unos puntos claves de cómo la empresa debe proceder para alcanzar los objetivos planteados.

Si el gran reto que tiene Confecciones S.A.C. es convertirse en los próximos 10 años en una de las empresas textiles de mayor éxito en el Perú, es necesario comenzar a pensar de forma estratégica: establecer unos lineamientos claros y procedimientos transparentes para tomar las decisiones más pertinentes en los asuntos corporativos vinculados a la empresa.

Asimismo, cabe mencionar que este sistema, dentro del plan de comunicación, resulta ser clave, estratégico y transcendental para un buen devenir en materia de comunicación. Una empresa como Confecciones S.A.C puede asumir altos riesgos de no contar con una adecuada guía de pautas de gobierno corporativo con un enfoque de desarrollo sostenible.

Entonces, según lo que menciona el caso, si el nuevo equipo administrativo está convencido de la necesidad de un área de comunicaciones, en el cual se sepa definir las líneas estratégicas de comunicación, y los requerimientos humanos y financieros para llevar a cabo dicho proceso, resulta transcendental contar con estas pautas que no solo dará base a la gestión a administrativa y operacional de la empresa, sino también dará soporte al plan de comunicación.

Uno puede desarrollar un buen plan estratégico de comunicación; sin embargo, estos lineamientos le brindan un orden y un horizonte claro a la gestión. Además, permite a la empresa estar siempre enfocada en todo momento y ante cualquier suceso que enfrente. Se trata de que la empresa mantenga una gestión coherente en sus procesos a nivel organizacional. 
Que lo que se "diga" también sea coherente con el "hacer" de la empresa textil. De esta forma, todo proceso de comunicación dirigido a los grupos de interés por parte de la empresa tendrá coherencia, sustento y genera valor en cada stakeholders. Se trata de buscar el mejor relacionamiento con cada grupo de interés, mediante la gestión adecuada de las comunicaciones tanto a nivel interno como externo.

A continuación, se presenta los puntos claves a tener en consideración en materia de buen gobierno corporativo y sostenibilidad:

1. Lograr que la visión, misión, objetivos y valores institucionales se reflejen en el comportamiento ético que la empresa Confecciones S.A.C desarrolle con sus grupos de interés.

2. Del mismo modo, fomentar y promover la transparencia en todos los procesos administrativos y operacionales de la organización.

3. Asimismo, todas las decisiones que se tomen en la organización deben ser informadas de forma clara y sencilla a todas las áreas correspondientes que componen a la empresa.

4. Es necesario establecer criterios claros y definidos para el cumplimiento del código de ética o conducta de la empresa.

5. Además, es necesario respetar las políticas de comunicación para la buena y adecuada gestión de la misma.

6. Con el transcurrir de los años, se debe ir haciendo la transición hacia un modelo de desarrollo sostenible, que involucre los impactos económicos, sociales y ambientales en relación con los grupos de interés.

7. Por ende, se debe busca implementar un modelo eficaz que incorpore la generación de valor compartido con los grupos de interés, considerando los Objetivos de Desarrollo Sostenible (ODS) dentro de su cadena de valor.

8. Por último, presentar informes y reportes estructurados para proporcionar transparencia y rendición de cuentas.

\section{Política de comunicación}

En línea con las pautas establecidas dentro del desarrollo de un buen gobierno corporativo, vinculado al aspecto de desarrollo sostenible, se considera conveniente 
desarrollar una política de comunicaciones que brinde soporte al plan estratégico de comunicación, con el fin de lograr una ventaja competitivo respecto a nuestros competidores.

Mediante esta política de comunicaciones, se espera contribuir al fortalecimiento de la cultura corporativa y generar un proceso de cambio a nivel interno en la organización, con el fin de establecer un clima laboral y adecuado para el buen ejercicio de funciones de los colaboradores. Que sirva de plataforma para que los colaboradores puedan sentirse en disposición de manifestarse y contribuir con ideas e iniciativas propias, generando sentido de pertenencia a la organización.

Los objetivos generales de una política de comunicación son los siguientes:

- Promover el compromiso de los colaboradores con los objetivos y metas de la empresa.

- Servir de herramienta para el fomento de los valores: peruanidad, calidad, compromiso con el medio ambiente, innovación y colaboración.

- Alienar los objetivos de la empresa con los objetivos de comunicación, mediante la implementación del plan de comunicaciones desarrollado por la empresa

- Lograr un buen nivel de colaboración, recepción y retroalimentación no solo con los colaboradores, sino entre todos los niveles de la organización (mandos medios, administrativos, operacional, plana gerencial)

- Obtener un buen nivel de comunicación descendente, ascendente y lateral que permita a la empresa estar permanentemente al tanto de los cambios producidos en el sector.

En ese sentido, la política de comunicaciones recae en los siguientes puntos:

- Política de puertas abiertas: cualquier miembro o colaborador de la empresa tiene el derecho de comunicarse directamente con el responsable de su área, de recursos humanos o el gerente general. De suscitarse un problema determinado, debe sentirse en la confianza suficiente para comunicarlo y darle algún tipo de solución a la brevedad. La prioridad debe ser el valor de nuestra gente.

- Mensajes claros y coherentes con los objetivos de la comunicación: el colaborador debe tener en cuenta e interiorizar los mensajes que transmite la 
organización. Para esto, es necesario que el mensaje esté alineado con los objetivos estratégicos, que se hacen extensivos a los diferentes grupos de interés.

- Participación activa: Fomentar el espacio para el desarrollo de una participación activa y positiva, con el fin de generar nuevos aportes en materia de ideas, sirviendo de insumo directo para diversos procesos de mejora que se implementen dentro de la organización.

- Branding corporativo: hacer uso responsable del manual de identidad corporativa que involucra la propuesta del logo y de la marca que la empresa se encuentra por sacar al mercado.

- Comunicar, ante todo: asegurar en base a una gestión adecuada que la comunicación sea ascendente, descendente, horizontal, flexible, clara, precisa, inmediata y estructurada con el fin de contribuir al desarrollo de una cultura corporativa sólida para generar compromiso.

Escucha activa: no solo se trata de recibir mensajes, sino de sentirse escuchado, valorado y que cada colaborador sea parte clave de la organización. Todo colaborador debe sentirse en la plena confianza de sentir escuchado y sean participes de cualquier tipo de conversación que involucre asuntos afines a la empresa.

- DirCom (responsable del proceso de comunicación): saber que todo colaborador debe acudir al DirCom para tratar asuntos de la empresa entre otros. Esto permite al DirCom alcanzar los objetivos generales y vincularlos con los objetivos del plan de comunicaciones, tomando en cuenta todo tipo de sugerencia que provenga de cualquier colaborador sea del área que sea.

En conclusión, se sugiere que esta política de comunicaciones propuesta, adherido al plan de comunicaciones, sirva de esqueleto organizacional para llevar a cabo todas las acciones pertinentes. La carencia de una política de comunicaciones impediría contribuir al cambio que busca la empresa en materia de cultura corporativa y gestión del cambio. En vista a la notoria insatisfacción del personal de colaboradores, 
considerando que solo apenas el $20 \%$ considera que son escuchados por sus superiores, resulta fundamental implementar dicha política. 


\section{PARTE 4}

\section{MAPEO DE GRUPOS DE INTERES}

\section{Importancia del mapeo de grupos de interés y la generación de valor compartido}

De acuerdo con Freeman, los stakeholders o grupos de interés son "cualquier grupo o individuo que puede afectar o ser afectado por la consecución de los objetivos de la empresa". Sin embargo, cabe precisar que no solamente se queda en la afectación del grupo de interés, sino que va más allá del propio asunto. Es decir que basado en el buen relacionamiento que debe gestionar la empresa Confecciones S.A.C. con sus respectivos grupos de interés, se toma prioridad identificar a todo grupo que tiene interés en ser relacionado con la organización, basado en las expectativas y necesidades que la parte interesada tiene con este último (citado en Argandoña, 1998).

Por ende, no se trata de simplemente buscar una razón práctica - que de hecho lo haydel por qué debo involucrarme con este stakeholders, sino, al margen de las razones comerciales o de otra índole que pueda existir, se debe priorizar la creación de valor compartido entre, acuñada por Michael E. Porter y Mark R. Kramer, en el cual se enfoca en las conexiones entre el progreso económico y el de la sociedad, ya sea reconcebiendo los productos y mercados, redefiniendo la productividad de la cadena de valor y permitiendo el desarrollo de un cluster local (Porter y Kramer, 2011)

En resumen, se trata de que la empresa Confecciones S.A.C, mediante este modelo citado, busque un claro relacionamiento y sinergia considerando el enorme potencial y valor diferencial que ofrece mediante la incorporación de la marca. Valores como calidad, peruanidad, compromiso con el medio ambiente, innovación y colaboración deben ser producto del reflejo de lo que representa la empresa para sus grupos de interés.

\section{Mapeo de grupos de interés}


A continuación, se presenta el siguiente mapeo de grupos de interés de la empresa Confecciones S.A.C con sus respectivas expectativas que permitirán generar sinergias y mayor involucramiento:

\begin{tabular}{|c|c|}
\hline de interés & Expectativas y necesidades \\
\hline $\begin{array}{l}\text { Colaboradores (Alta dirección): nuevo } \\
\text { equipo gerencial compuesto por distintos } \\
\text { profesionales. Entre ellos diseñadores, } \\
\text { ingenieros industriales, administradores y } \\
\text { profesionales de marketing. Tomadores de } \\
\text { decisiones. }\end{array}$ & $\begin{array}{l}\text { La expectativa de este grupo de interés es } \\
\text { alta. Son ellos quienes están convencidos } \\
\text { de la necesidad de implementar un área de } \\
\text { comunicaciones, con el fin de establecer } \\
\text { líneas estratégicas de comunicación de } \\
\text { forma transversal en la organización. }\end{array}$ \\
\hline $\begin{array}{l}\text { Colaboradores (área de marketing): } \\
\text { compuesto por profesionales de } \\
\text { marketing, su visión principalmente recae } \\
\text { en lo comercial y requiere del área de } \\
\text { comunicaciones para aportar al } \\
\text { lanzamiento de la marca }\end{array}$ & $\begin{array}{l}\text { Si bien la expectativa de todos los grupos } \\
\text { de interés internos de la empresa debe ser } \\
\text { relevante, esta área tiene una necesidad } \\
\text { clara, dado que Comunicaciones trabajará } \\
\text { de la mano con dicha área. Se busca que } \\
\text { exista una retroalimentación excelente, } \\
\text { basado en la información oportuna y } \\
\text { trabajo en equipo entre ambas áreas. }\end{array}$ \\
\hline $\begin{array}{l}\text { Colaboradores (área administrativa): } \\
\text { compuesta por todas las áreas que trabajan } \\
\text { en la empresa. }\end{array}$ & $\begin{array}{l}\text { La expectativa de este grupo de interés es } \\
\text { mediana. Se busca que ellos de antemano } \\
\text { conozcan qué valor puede aportar un área } \\
\text { de comunicaciones a la organización. Por } \\
\text { su parte, existe disposición para llevar a } \\
\text { cabo el plan de comunicaciones, sujeto a } \\
\text { la política de comunicaciones propuesta } \\
\text { ya adherida a dicho plan, que involucra a } \\
\text { todos los colaboradores de forma } \\
\text { transversal. }\end{array}$ \\
\hline Colaboradores & La expectatuva \\
\hline
\end{tabular}




\begin{tabular}{|c|c|}
\hline $\begin{array}{l}\text { Son aquellas personas, en su mayoría } \\
\text { mujeres, quienes disponen del arduo } \\
\text { trabajo que implica la elaboración, } \\
\text { confección y diseño de las prendas. }\end{array}$ & $\begin{array}{l}\text { alta. Buscan estar motivadas para el } \\
\text { desarrollo de sus capacidades y } \\
\text { creatividad al momento de plasmar sus } \\
\text { diseños. El área de Comunicaciones debe } \\
\text { abordar este punto en concreto, } \\
\text { fortaleciendo un estrecho lazo de } \\
\text { confianza y trabajo en equipo que fomente } \\
\text { el desarrollo de una cultura corporativa } \\
\text { sólida. }\end{array}$ \\
\hline $\begin{array}{l}\text { Proveedores (personal ubicado en } \\
\text { Arequipa y Ayacucho): grupo de interés } \\
\text { clave, cuya responsabilidad recae todo el } \\
\text { tema de la selección y distribución de } \\
\text { telas de algodón pima, entre otros. }\end{array}$ & $\begin{array}{l}\text { La expectativa de este grupo de interés es } \\
\text { alta. Si la empresa Confecciones S.A.C } \\
\text { busca un cambio en sus procesos de } \\
\text { producción, sus proveedores deben estar } \\
\text { alienados a dicho objetivo. } \\
\text { Comunicaciones debe ser el puente entre } \\
\text { la empresa y los proveedores. }\end{array}$ \\
\hline $\begin{array}{l}\text { Accionista (socios o fundadores): desde } \\
\text { su fundación, la empresa ha venido } \\
\text { creciendo gracias a la energía que le } \\
\text { pusieron sus fundadores, tres socios } \\
\text { capitalinos con fuertes lazos hacia sus } \\
\text { proveedores en provincias. }\end{array}$ & $\begin{array}{l}\text { Su expectativa varía en función de las } \\
\text { áreas de su interés. Desde el área de } \\
\text { Comunicaciones, debe existir una } \\
\text { preocupación clara por la rendición de } \\
\text { cuentas. El lineamiento de buen gobierno } \\
\text { corporativo y la política de } \\
\text { comunicaciones fortalecerá mejor las } \\
\text { relaciones y buen relacionamiento con } \\
\text { este stakeholders. }\end{array}$ \\
\hline $\begin{array}{l}\text { Clientes (marcas internacionales): } \\
\text { siendo la empresa Confecciones S.A.C un } \\
\text { proveedor clave de diversas marcas del } \\
\text { exterior. }\end{array}$ & $\begin{array}{l}\text { Necesidad básica de expandir mercados } \\
\text { europeos y norteamericanos. Se sebe } \\
\text { trabajar principalmente por el comercio } \\
\text { electrónico y posicionamiento web. }\end{array}$ \\
\hline Clientes & ellos \\
\hline
\end{tabular}




\begin{tabular}{|c|c|}
\hline $\begin{array}{l}\text { aquellas personas, en su mayoría jóvenes, } \\
\text { que se preocupan por el medio ambiente y } \\
\text { la justicia social y desean comprar } \\
\text { productos que no dañen el planeta, } \\
\text { desarrollando un consumo sostenible. }\end{array}$ & $\begin{array}{l}\text { buscar más alternativas de empresas que } \\
\text { apuesten por la moda sostenible, } \\
\text { empleando la distribución y } \\
\text { comercialización de prendas eco } \\
\text { amigables. Se trata de informar y } \\
\text { concientizar. }\end{array}$ \\
\hline $\begin{array}{l}\text { Estado (entidades públicas): en este } \\
\text { grupo entran entidades como Promperú, } \\
\text { Mincetur o el MTPE que vienen } \\
\text { trabajando en promover el sector de la } \\
\text { moda sostenible en los mercados } \\
\text { internacionales }\end{array}$ & $\begin{array}{l}\text { La expectativa de estas entidades es } \\
\text { regular hasta cierto punto, dado que una } \\
\text { empresa del sector, si busca mayor } \\
\text { orientación o introducirse al campo del } \\
\text { sector textil, necesariamente va tener que } \\
\text { acercarse a dichas instituciones. Desde el } \\
\text { área de Comunicaciones se puede abordar } \\
\text { a modo de alianzas estratégicas. }\end{array}$ \\
\hline $\begin{array}{l}\text { Medios de comunicación: medios locales } \\
\text { de prensa escrita, radial o televisiva que } \\
\text { les pueda interesar el tema del consumo } \\
\text { responsable. }\end{array}$ & $\begin{array}{l}\text { La expectativa es baja, dado que el tema } \\
\text { aún es desconocido no solo por los } \\
\text { medios, sino por los usuarios o } \\
\text { consumidores, quienes podrían exigir } \\
\text { mayor fomento de esta industria en el } \\
\text { país. El área de Comunicaciones debe } \\
\text { poco a poco ir posicionando más el tema } \\
\text { con el fin de alcanzar mayor presencia en } \\
\text { los medios. }\end{array}$ \\
\hline $\begin{array}{l}\text { Comunidad y medio ambiente (zona de } \\
\text { influencia): en este escenario, entra a } \\
\text { tallar la zona de influencia en donde opera } \\
\text { los principales proveedores de la empresa } \\
\text { textil. En este grupo puede entrar los } \\
\text { vecinos, jóvenes, entidades públicas, } \\
\text { municipalidades o hasta el propio }\end{array}$ & $\begin{array}{l}\text { La expectativa dependerá del grado de } \\
\text { influencia negativa de la empresa que } \\
\text { genere en la zona de influencia. Se busca } \\
\text { revertir la situación en base a la ética y } \\
\text { transparencia de los procesos de } \\
\text { producción, gestión y relacionamiento de } \\
\text { la organización. }\end{array}$ \\
\hline
\end{tabular}




\begin{tabular}{|l|l|}
\hline visitante extranjero o local. & \\
\hline Competidores (competencia que ya se & Expectativa regular/ alta, ya que siempre \\
encuentra en la tendencia de la moda & la competencia va estar mirando que hace \\
sostenible): este grupo lo conforman & la empresa del lado en estos temas. El \\
aquellas empresas comerciales o empresas & área de comunicaciones debe tener en \\
sociales que ya se encuentran en el & cuenta que es un reto lanzar una propia \\
mercado, ofreciendo productos eco & marca y posicionarlo en la mente del \\
amigables a un consumidor que dista del & potencial consumidor para diferenciarse \\
concepto de comprar y tirar (fast fashion) & del resto de competidores. \\
\hline $\begin{array}{l}\text { Alianzas (aliados estratégicos): este } \\
\text { grupo lo conforman instituciones sin fines } \\
\text { de lucro, entidades públicas o privadas o }\end{array}$ & $\begin{array}{l}\text { La expectativa va ser de regular o baja, } \\
\text { dado que es necesario repotenciar las } \\
\text { el propio ciudadano de pie, que busca }\end{array}$ \\
$\begin{array}{l}\text { apoyar este tipo de iniciativas que } \\
\text { contribuya al desarrollo sostenible del }\end{array}$ & situación. \\
sector. & \\
\hline
\end{tabular}




\section{PARTE 5}

\section{ESTRUCTURA Y COMPETENCIAS DEL ÁREA DE COMUNICACIÓN}

\section{Distinción de competencias:}

Si la visión de Confecciones S.A.C es convertirse en los próximos 10 años en una de las empresas textiles de mayor éxito en el Perú, sumado al reto de lograr una mayor innovación tecnológica para impulsar aún más ese crecimiento, considerando una visión de desarrollo sostenible - que incluya las alianzas estratégicas en función de los 17 Objetivos de Desarrollo Sostenible (ODS)-, basada en la ética y transparencia de los procesos de producción, gestión y relacionamiento de las organizaciones del sector; resulta impensable lograrlo sin la implementación de un área de comunicaciones.

Frente a ese escenario, resulta clave contar con un área de comunicaciones, que cuente con la capacidad técnica y brinde soporte para que pueda abordar todos los asuntos comunicacionales que la empresa afronte en el día a día. En este sentido, el área de comunicaciones debe contar con competencias basadas en líneas de acción, que recaen bajo la responsabilidad del departamento y de su capacidad de decisión. Velar por la comunicación interna, externa, las relaciones con los medios, las alianzas estratégicas, comunicación digital basada en el comercio electrónico, responsabilidad por la propuesta de marca e implementación y seguimiento de la política de comunicaciones son solo algunas de sus competencias.

Objetivo estratégico que aborda el campo de las comunicaciones: establecer y organizar la implementación de un área de comunicación, adecuándolo a las necesidades comunicativas de la empresa "Kuyu Ecotextil" y a las áreas de conocimiento y habilidades de cada uno de sus componentes.

\section{Estructura del área de comunicaciones:}

- Director de comunicaciones (DirCom)

- Responsable de marketing digital

- Responsable de comunicación interna

- Responsable de comunicación externa y asuntos corporativos 
- Responsable de promoción y eventos

- Responsable de prensa y relaciones públicas

- Responsable de sostenibilidad

- Responsable de diseño gráfico 


\section{PARTE 6}

\section{PLAN ESTRATÉGICO DE COMUNICACIÓN}

Tras haber realizado una investigación a la industria textil tanto a nivel internacional como local, sumado al desarrollo del DAFO de comunicación establecido, vemos que gran parte de las debilidades de la empresa Confecciones S.A.C. se debe a la carencia de una adecuada gestión de la comunicación, por lo mismo que no existe un área como tal. Esto ha repercutido, por ejemplo, en el poco trabajo realizado con las colaboradoras, quien representan el aval o talento humano más importante de la empresa. El segundo factor de debilidades que se extrae del análisis DAFO recae en la situación que, pese a que en los últimos años han conseguido cierto éxito en el sector textil, resulta complicado seguir expandiendo mercado con ese nombre de por sí.

Respondiendo a estas necesidades comunicacionales, considerando el análisis del sector industrial textil y el DOFA comunicacional, se han planteado los siguientes objetivos en materia de comunicación:

\begin{tabular}{|l|l|l|}
\hline $\begin{array}{l}\text { prioridad estratégica de la la } \\
\text { organización: }\end{array}$ & $\begin{array}{l}\text { Dar a conocer la corporación y la nueva } \\
\text { marca entre los principales grupos de } \\
\text { interés, asociándola a los valores: } \\
\text { peruanidad, calidad, compromiso con el } \\
\text { medio ambiente vinculado al desarrollo } \\
\text { sostenible, innovación y colaboración. }\end{array}$ \\
\hline $\begin{array}{l}\text { Primer objetivo de comunicación (¿Qué } \\
\text { quiero alcanzar?) }\end{array}$ & $\begin{array}{l}\text { Dar a conocer a la organización “Kuyu } \\
\text { Ecotextil" como una empresa peruana } \\
\text { líder del sector textil que busca destacar } \\
\text { por su calidad y compromiso con el medio } \\
\text { ambiente, empleando materias primas eco } \\
\text { amigables. }\end{array}$ \\
\hline $\begin{array}{l}\text { Eje o pilar estratégico (vinculado al } \\
\text { ámbito o enfoque de acción a desarrollar }\end{array}$ & \\
\hline
\end{tabular}




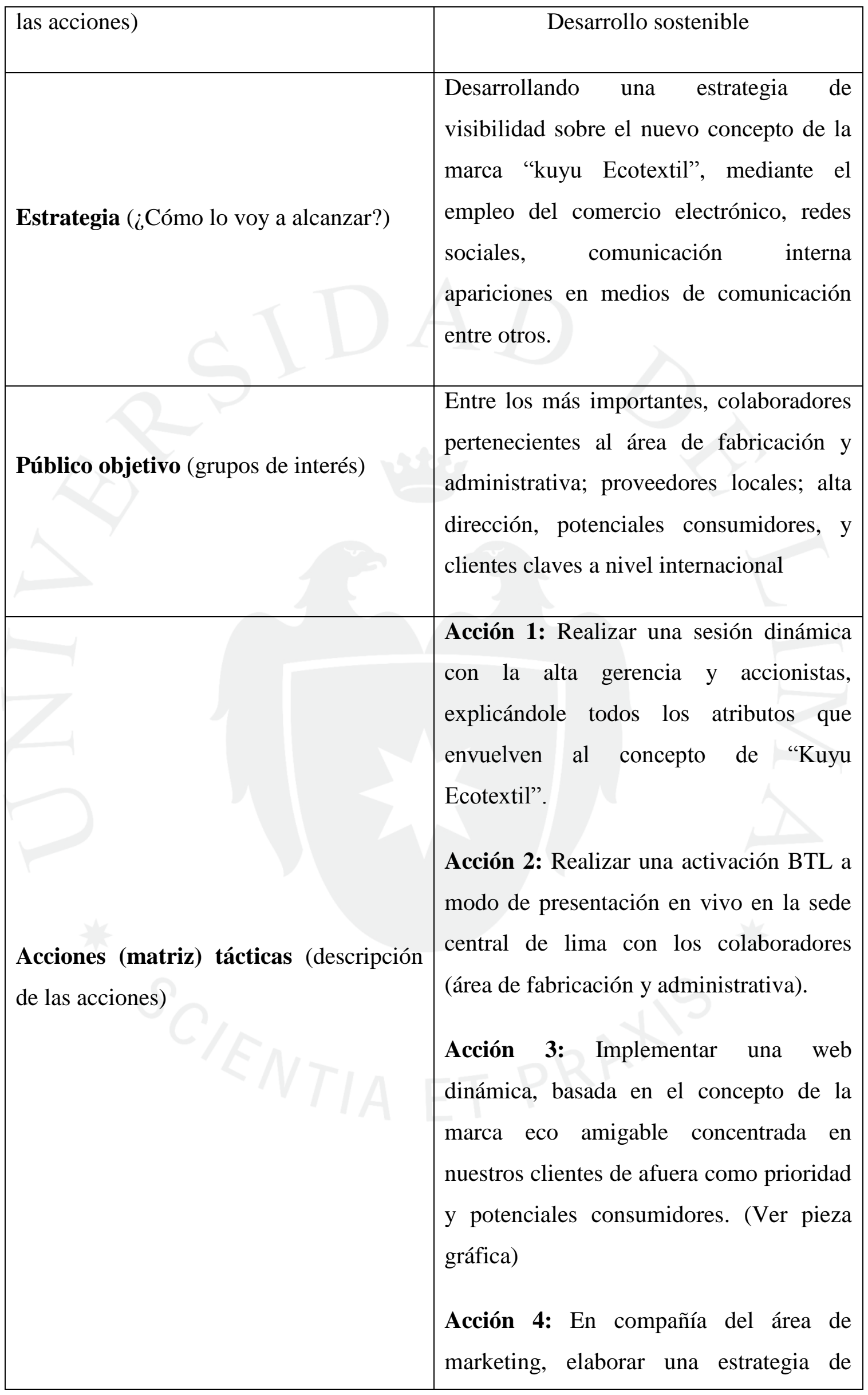




\begin{tabular}{|c|c|}
\hline & $\begin{array}{l}\text { marketing de contenidos en redes sociales, } \\
\text { que enfatice la apuesta por la moda } \\
\text { sostenible. }\end{array}$ \\
\hline & $\begin{array}{l}\text { Acción 5: realizar visitas a los } \\
\text { proveedores ubicados en las sedes de } \\
\text { Arequipa y Ayacucho, con el fin de } \\
\text { informar el relanzamiento de la marca } \\
\text { "Kuyu Ecotextil" }\end{array}$ \\
\hline & $\begin{array}{l}\text { Acción 6: establecer una base de medios } \\
\text { de comunicación en los cuales la empresa } \\
\text { se encuentre interesada en tener mayor } \\
\text { exposición. }\end{array}$ \\
\hline & 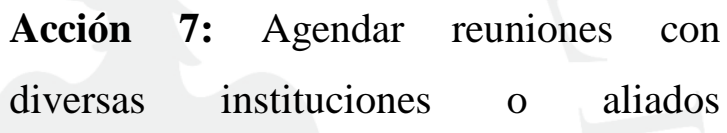 \\
\hline & $\begin{array}{l}\text { estratégicos con dar a conocer la marca. } \\
\text { En mente se tiene pensado a Mincetur, } \\
\text { Programa Perú Responsable del MTPE y } \\
\text { Promperú. }\end{array}$ \\
\hline Responsabilidad de trabajo & Área de comunicaciones y marketing \\
\hline Meta & $\begin{array}{l}\text { Lograr que un } 50 \% \text { de los grupos de } \\
\text { interés sepan de la existencia de la marca } \\
\text { y reconozcan a la misma por los atributos } \\
\text { mencionados en un lapso de } 6 \text { meses } \\
\text { aproximadamente. }\end{array}$ \\
\hline & $\begin{array}{l}\text { Acción 1: nivel de conocimiento y } \\
\text { aceptación por parte del concepto de la } \\
\text { marca y de los atributos incorporados. } \\
\text { Herramienta de medición: Focus group y }\end{array}$ \\
\hline
\end{tabular}




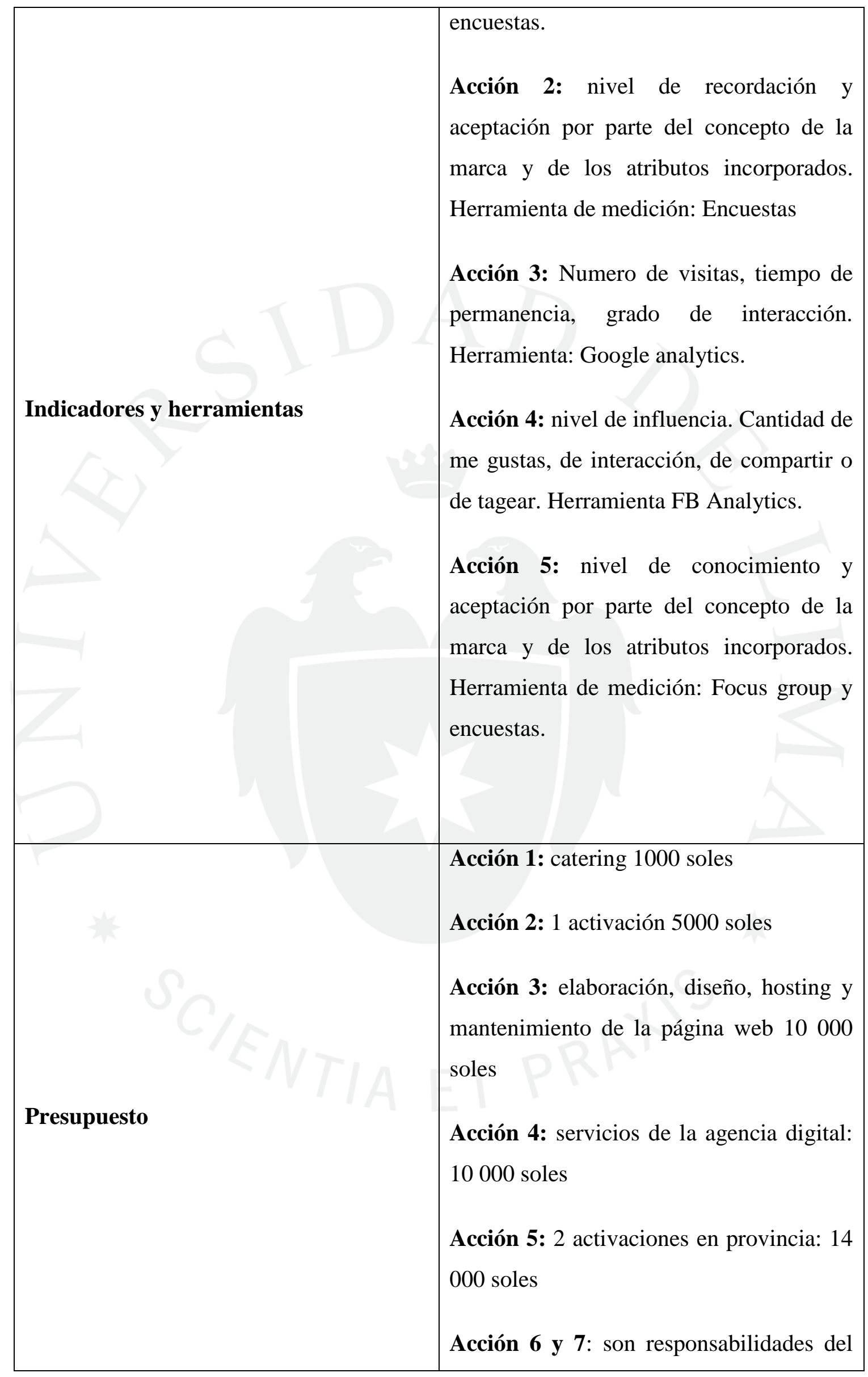




\begin{tabular}{|l|l|}
\hline $\begin{array}{l}\text { área de comunicación, cuyo costo forma } \\
\text { parte de sus funciones. }\end{array}$ \\
\hline
\end{tabular}

\begin{tabular}{|c|c|}
\hline $\begin{array}{l}2 \text { prioridad estratégica de } \\
\text { organización: }\end{array}$ & $\begin{array}{l}\text { La organización destaca por sus } \\
\text { elementos diferenciadores en relación a } \\
\text { sus competidores, apostando por la } \\
\text { calidad de sus materias primas y diseños } \\
\text { innovadores, sumado a la preocupación de } \\
\text { la marca con el medio ambiente con } \\
\text { fuertes componentes de responsabilidad } \\
\text { social para ofrecer los mejores acabados a } \\
\text { los potenciales consumidores. }\end{array}$ \\
\hline $\begin{array}{l}\text { Segundo objetivo de comunicación } \\
\text { (¿Qué quiero alcanzar?) }\end{array}$ & $\begin{array}{l}\text { Informar y sensibilizar al potencial } \\
\text { consumidor acerca de nuestros productos } \\
\text { de calidad, empleando materias primas } \\
\text { eco amigables con el toque de peruanidad } \\
\text { que caracteriza a la marca "Kuyu } \\
\text { Ecotextil" }\end{array}$ \\
\hline $\begin{array}{l}\text { Eje o pilar estratégico (vinculado al } \\
\text { ámbito o enfoque de acción a desarrollar } \\
\text { las acciones) }\end{array}$ & Consumo responsable \\
\hline Estrategia (¿Cómo lo voy a alcanzar?) & $\begin{array}{l}\text { Desarrollando una estrategia de } \\
\text { visibilidad sobre el nuevo concepto de la } \\
\text { marca "kuyu Ecotextil", mediante el } \\
\text { empleo del comercio electrónico, redes } \\
\text { sociales, comunicación interna } \\
\text { apariciones en medios de comunicación } \\
\text { entre otros. }\end{array}$ \\
\hline
\end{tabular}




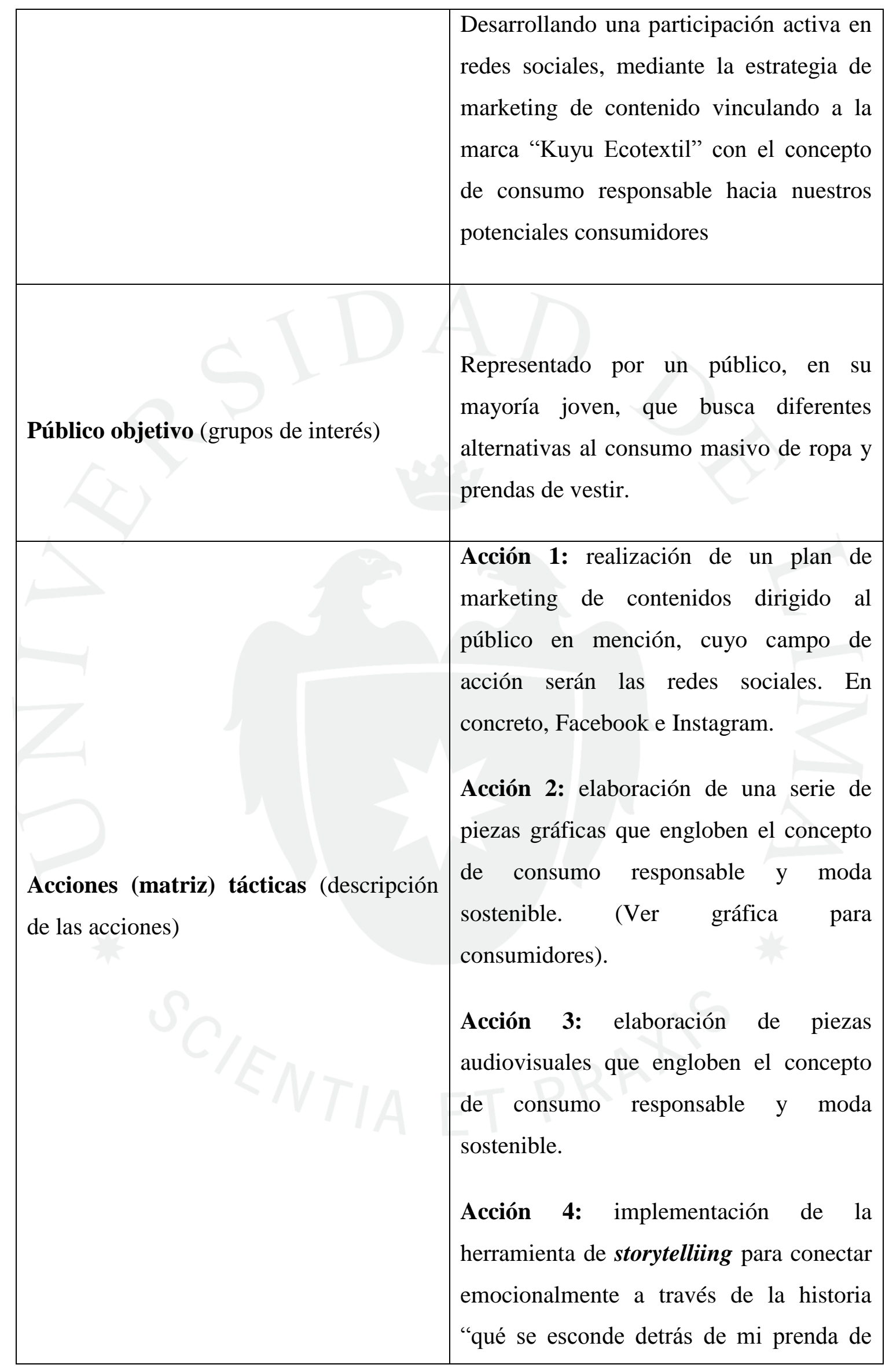




\begin{tabular}{|c|c|}
\hline & vestir" con los potenciales consumidores \\
\hline Responsabilidad de trabajo & Área de comunicación y marketing \\
\hline Meta & $\begin{array}{l}\text { Lograr que un } 50 \% \text { de los potenciales } \\
\text { consumidores reconozcan a "Kuyu } \\
\text { Ecotextil" por ser una empresa que } \\
\text { apuesta por el consumo responsable y } \\
\text { moda sostenible. }\end{array}$ \\
\hline Indicadores y herramientas & $\begin{array}{l}\text { Todas las acciones de esta sección, al } \\
\text { estar concentradas en un plan de } \\
\text { marketing de contenidos, se pueden } \\
\text { medir de la siguiente manera: nivel de } \\
\text { viralización de las publicaciones en redes } \\
\text { sociales, comentarios generados por el } \\
\text { contenido, nivel de aceptación por parte } \\
\text { de la audiencia. Herramienta: FB } \\
\text { Analytics. }\end{array}$ \\
\hline Presupuesto & $\begin{array}{l}\text { Armado del plan de marketing de } \\
\text { contenidos, incluyendo seguimiento, } \\
\text { evaluación y asesoría: } 15000 \text { soles }\end{array}$ \\
\hline
\end{tabular}

\begin{tabular}{|l|l|l|}
\hline $\begin{array}{l}\text { prioridad estratégica de la } \\
\text { organización: }\end{array}$ & $\begin{array}{l}\text { La empresa ve necesario elevar el grado } \\
\text { de involucramiento de los proveedores y } \\
\text { aliados estratégicos respecto del valor: } \\
\text { compromiso con el medio ambiente, bajo } \\
\text { un enfoque de desarrollo sostenible y } \\
\text { ODS }\end{array}$ \\
\hline Tercer objetivo de comunicación (¿Qué & Construir una comunicación más fluida \\
\hline
\end{tabular}




\begin{tabular}{|c|c|}
\hline quiero alcanzar?) & $\begin{array}{l}\text { con los proveedores tanto locales como } \\
\text { con los de provincia, en la cual } \\
\text { busquemos ser aliados estratégicos en } \\
\text { tanto nos involucremos en un concepto de } \\
\text { cadena de valor responsable. }\end{array}$ \\
\hline $\begin{array}{l}\text { Eje o pilar estratégico (vinculado al } \\
\text { ámbito o enfoque de acción a desarrollar } \\
\text { las acciones) }\end{array}$ & Cadena de valor responsable \\
\hline Estrategia (¿Cómo lo voy a alcanzar?) & $\begin{array}{l}\text { Desarrollando una participación activa e } \\
\text { involucraría con los proveedores que } \\
\text { vincule la apuesta que "Kuyu Ecotextil" } \\
\text { realiza en materia de desarrollo sostenible } \\
\text { con la importancia de desarrollar una } \\
\text { cadena de valor responsable, que } \\
\text { beneficie al proveedor. }\end{array}$ \\
\hline Público objetivo (grupos de interés) & $\begin{array}{l}\text { Principales proveedores de Arequipa y } \\
\text { Ayacucho }\end{array}$ \\
\hline $\begin{array}{l}\text { Acciones (matriz) tácticas (descripción } \\
\text { de las acciones) }\end{array}$ & $\begin{array}{l}\text { Acción 1: Desarrollo de talleres } \\
\text { semanales, con el fin de informar y } \\
\text { sensibilizar todo lo relacionado a una } \\
\text { cadena de valor responsable. (Ver gráfica) } \\
\text { Acción 2: contratar a un especialista en la } \\
\text { materia a modo de capacitación a los } \\
\text { proveedores de regiones. } \\
\text { Acción 3: implementación de la } \\
\text { herramienta de storytelliing para conectar } \\
\text { emocionalmente a través de la historia } \\
\text { "qué se esconde detrás de una cadena de }\end{array}$ \\
\hline
\end{tabular}




\begin{tabular}{|c|c|}
\hline & $\begin{array}{l}\text { valor" con los proveedores. } \\
\text { Acción 4: visitas semanales para } \\
\text { transmitir los valores de la marca "Kuyu } \\
\text { Ecotextil" }\end{array}$ \\
\hline Responsabilidad de trabajo & Área de comunicación y marketing \\
\hline Meta & $\begin{array}{l}\text { Lograr que un } 40 \% \text { de los proveedores } \\
\text { reconozcan a "Kuyu Ecotextil" por ser } \\
\text { una empresa que, apuesta por el desarrollo } \\
\text { sostenible, fomentando la incorporación } \\
\text { de una adecuada cadena de valor } \\
\text { responsable. }\end{array}$ \\
\hline$b^{\prime}$ & $\begin{array}{l}\text { Acción 1: Nivel de aceptación de los } \\
\text { talleres. Herramienta: Focus Group }\end{array}$ \\
\hline Indicadores y herramientas & $\begin{array}{l}\text { Acción 2: programa de sugerencias para } \\
\text { evaluar al especialista. Herramienta: } \\
\text { entrevistas presenciales. } \\
\text { Acción 3: Nivel de impacto del material } \\
\text { audiovisual. Herramienta: Encuestas. } \\
\text { Acción 4: nivel de conocimiento y } \\
\text { recordación de la marca. Herramienta: } \\
\text { formularios. }\end{array}$ \\
\hline Presupuesto & $\begin{array}{l}\text { Acción } 1,3 \text { y } 4 \text { son parte de la } \\
\text { responsabilidad del área de comunicación. } \\
\text { Acción 2: rango de precio de } 1 \\
\text { especialista por dictado de un solo taller: } \\
8000 \text { soles. }\end{array}$ \\
\hline
\end{tabular}




\begin{tabular}{|c|c|}
\hline $\begin{array}{l}4 \text { prioridad estratégica de la } \\
\text { organización: }\end{array}$ & $\begin{array}{l}\text { Es también prioridad fortalecer y } \\
\text { cohesionar a los colaboradores con } \\
\text { emprendimientos a través de la creación } \\
\text { de una cultura corporativa innovadora con } \\
\text { fuertes raíces nacionales. El } \\
\text { involucramiento de los colaboradores con } \\
\text { los nuevos objetivos y valores de la } \\
\text { organización deben beneficiar el clima } \\
\text { laboral y ser coherentes con la marca. }\end{array}$ \\
\hline $\begin{array}{l}\text { Cuarto objetivo de comunicación (¿Qué } \\
\text { quiero alcanzar?) }\end{array}$ & $\begin{array}{l}\text { Contribuir con el fortalecimiento de un } \\
\text { sentido de pertenencia entre los } \\
\text { colaboradores que responda a los valores: } \\
\text { peruanidad, calidad y respeto con el } \\
\text { medio ambiente. }\end{array}$ \\
\hline $\begin{array}{l}\text { Eje o pilar estratégico (vinculado al } \\
\text { ámbito o enfoque de acción a desarrollar } \\
\text { las acciones) }\end{array}$ & Cultura corporativa y gestión del cambio \\
\hline Estrategia (¿Cómo lo voy a alcanzar?) & $\begin{array}{l}\text { Desarrollando una cultura de puertas } \\
\text { abiertas con los colaboradores, con el fin } \\
\text { de revalorizar su rol dentro de la empresa. }\end{array}$ \\
\hline Público objetivo (grupos de interés) & $\begin{array}{l}\text { Colaboradoras, en su mayoría mujeres, de } \\
\text { la parte de producción }\end{array}$ \\
\hline $\begin{array}{l}\text { Acciones (matriz) tácticas (descripción } \\
\text { de las acciones) }\end{array}$ & $\begin{array}{l}\text { Acción 1: realización de un programa de } \\
\text { empoderamiento y liderazgo femenino } \\
\text { para potenciar capacidades "Manos que } \\
\text { tejen sueños" (Ver gráfica) } \\
\text { Acción 2: Charlas semanales para } \\
\text { sensibilizar de cada valor fomentado por }\end{array}$ \\
\hline
\end{tabular}




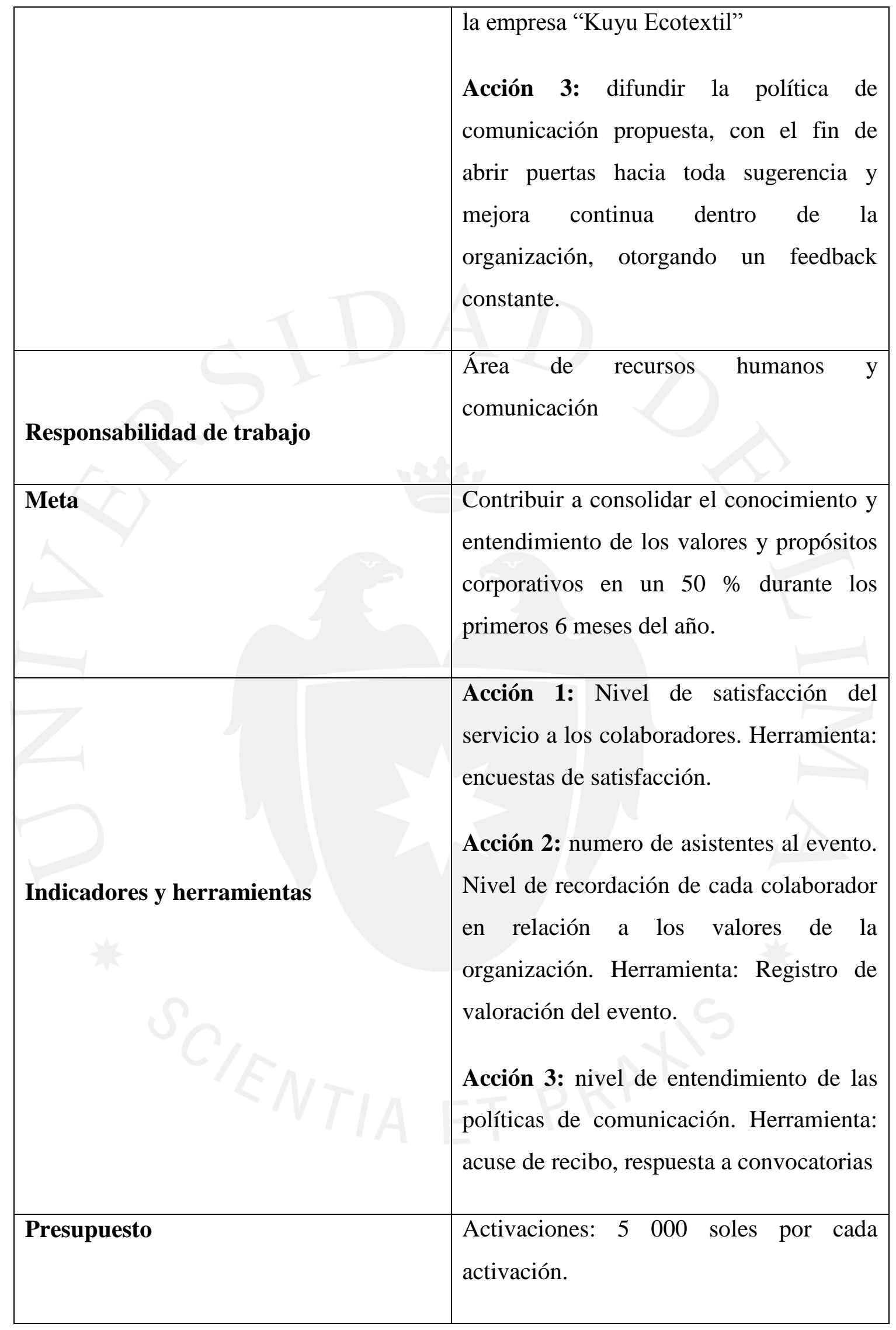




\section{Cronograma 2019}

\section{Enero}

- Presentación del área de comunicaciones a todas las áreas de la empresa

- Implementación del programa de empoderamiento y liderazgo femenino (será semanal)

- Charla semanal de fomento de valores de la organización

\section{Febrero}

- Fomento de la importancia de un área de comunicaciones a todas las áreas de la empresa (ver gráfica)

- Programa de empoderamiento y liderazgo femenino

- Charla semanal de fomento de valores de la organización

- Difusión de la política de comunicación propuesta, con el fin de abrir puertas hacia toda sugerencia y mejora continua dentro de la organización, otorgando un feedback constante.

\section{Marzo}

- Fomento de la importancia de un área de comunicaciones a todas las áreas de la empresa (ver gráfica)

- Programa de empoderamiento y liderazgo femenino

- Charla semanal de fomento de valores de la organización

- Difusión de la política de comunicación propuesta, con el fin de abrir puertas hacia toda sugerencia y mejora continua dentro de la organización, otorgando un feedback constante.

\section{Abril}

- Programa de empoderamiento y liderazgo femenino

- Charla semanal de fomento de valores de la organización

- Difusión de la política de comunicación propuesta, con el fin de abrir puertas hacia toda sugerencia y mejora continua dentro de la organización, otorgando un feedback 
constante.

\section{Mayo}

- Finalización del programa de empoderamiento y liderazgo femenino

- Charla semanal de fomento de valores de la organización

- Difusión de la política de comunicación propuesta, con el fin de abrir puertas hacia toda sugerencia y mejora continua dentro de la organización, otorgando un feedback constante.

\section{Junio}

- Evaluación del programa de empoderamiento y liderazgo femenino

- Finalización de ccharlas semanales de fomento de valores de la organización

- Evaluación de las colaborados respecto a los programas e iniciativas implementadas.

- Evaluación de la difusión de la política de comunicación propuesta, con el fin de abrir puertas hacia toda sugerencia y mejora continua dentro de la organización, otorgando un feedback constante.

\section{Julio}

- Desarrollo de la sesión dinámica con alta gerencia y accionistas, explicándole todos los atributos que envuelven al concepto de "Kuyu Ecotextil".

- Realizar una activación BTL a modo de presentación en vivo en la sede central de lima con los colaboradores (área de fabricación y administrativa).

- Implementación de una web.

- Establecer una base de medios de comunicación en los cuales la empresa se encuentre interesada en tener mayor exposición.

- Agendar reuniones con diversas instituciones o aliados estratégicos con dar a conocer la marca. En mente se tiene pensado a Mincetur, Programa Perú 


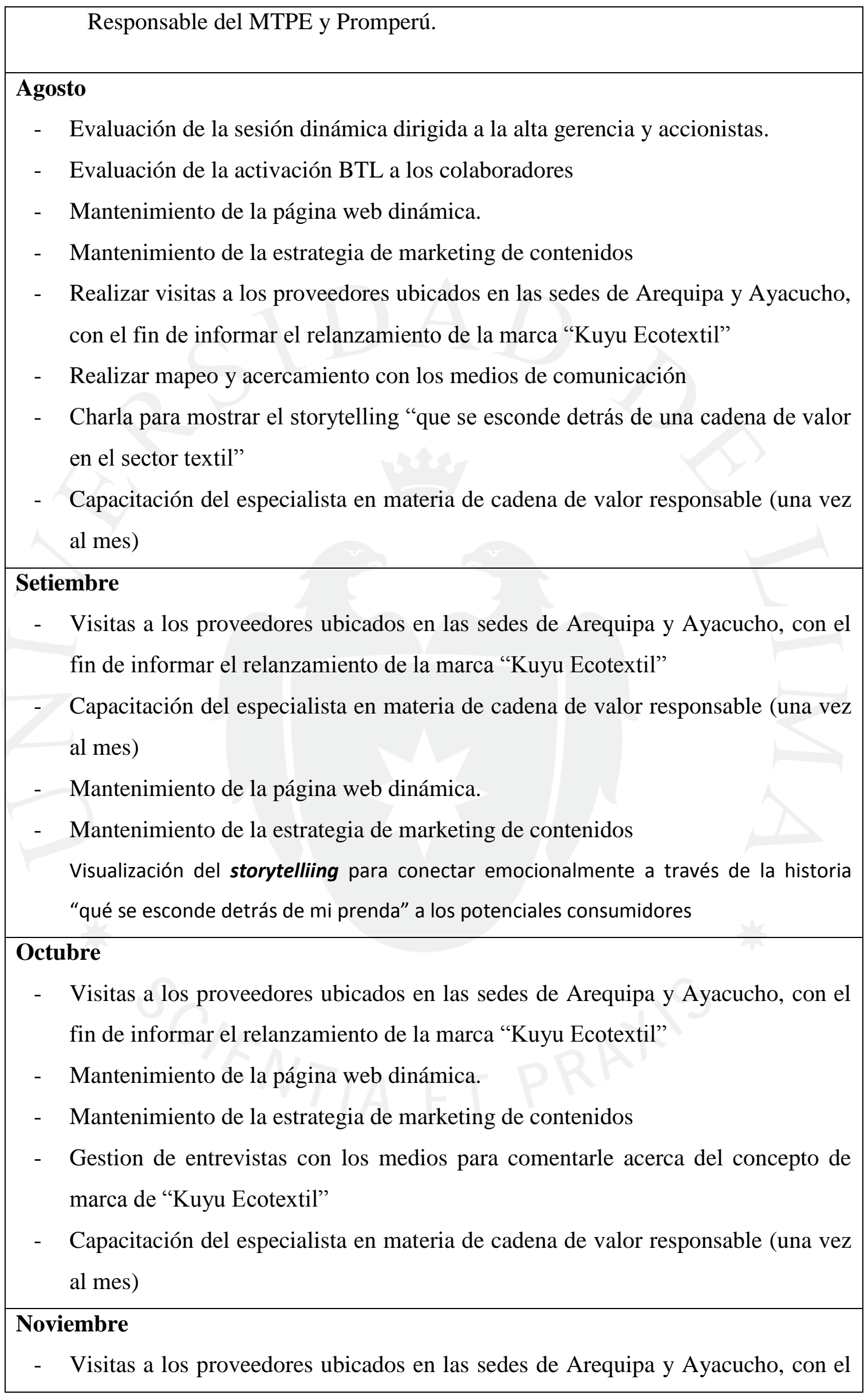


fin de informar el relanzamiento de la marca "Kuyu Ecotextil"

- Mantenimiento de la página web dinámica.

- Mantenimiento de la estrategia de marketing de contenidos

- Capacitación del especialista en materia de cadena de valor responsable (una vez al mes)

\section{Diciembre}

- Visitas a los proveedores ubicados en las sedes de Arequipa y Ayacucho, con el fin de informar el relanzamiento de la marca "Kuyu Ecotextil"

- Mantenimiento de la página web dinámica.

- Mantenimiento de la estrategia de marketing de contenidos

- Capacitación del especialista en materia de cadena de valor responsable (una vez al mes) 


\section{REFERENCIAS}

Argandoña, A. (1998). La teoría de los stakeholders y el bien común. (documento de investigación). Universidad de Navarra.

Bardales, E. (9 de febrero del 2018). Empresas de confecciones deben incorporar la innovación tecnológica, ¿cuánto es el costo?. Recuperado de https://gestion.pe/economia/empresas-confecciones-deben-incorporarinnovacion-tecnologica-costo-226939

Blanco, D. (21 de marzo del 2015). El mundo enfrentará una severa escasez de agua en 2030: ONU. Recuperado de http://www.elfinanciero.com.mx/mundo/elmundo-enfrentara-una-severa-escasez-de-agua-en-2030-onu

Campaña Ropa Limpia. (23 de octubre del 2013). Campaña Ropa Limpia exige el fin de los salarios de miseria en el sector textil. Recuperado de https://ropalimpia.org/noticias/campana-ropa-limpia-exige-el-fin-de-los-salariosde-miseria-en-el-sector-textil/

Capriotti, P. (1999). Comunicación Corporativa: una estrategia de éxito a corto plazo. Reporte C\&D Capacitación y Desarrollo, (13), 1-6. Recuperado de http://bidireccional.net/Blog/Comunicacion_Corporativa_1.pdf

Catorce6 (13 de marzo del 2018). Las alarmantes cifras de contaminación en el sector de la moda y el riesgo del 'fast fashion'. Recuperado de https://www.catorce6.com/actualidad-ambiental/internacional/15396-lasalarmantes-cifras-de-contaminacion-en-el-sector-de-la-moda-y-el-riesgo-delfast-fashion

Chouinard, Y., Ellison, J., y Ridgeway, R. (2011). La Economía Sustentable. Harvard Business Review. 89(9), 26-38. Recuperado de https://dialnet.unirioja.es/servlet/articulo? codigo $=3766988$

Costa, J. (2012). El DirCom hoy: dirección y gestión de la comunicación en la nueva economía. (7.ed.). Barcelona: Costa Punto Com.

El Comercio. (12 de abril del 2018). CCL: Exportaciones de confecciones a EE.UU. crecieron 3,6\%. Recuperado de https://elcomercio.pe/economia/peru/cclexportaciones-confecciones-ee-uu-crecieron-3-6-noticia-511558 
Esme Escuela de Moda. (s.f.). Fast fashion. Recuperado de https://www.esme.es/fastfashion/

Farré, J. (30 de diciembre del 2015). La industria textil y de la confección en Alemania. Recuperado de http://www.int-team.com/la-industria-textil-y-de-la-confeccionen-alemania/

Fernández, V. (s.f.). Las microfibras de la ropa contaminan los océanos. Recuperado de https://geoinnova.org/blog-territorio/microfibras-contamina-los-oceanos/

Flores Konja, J. y Rizas Flores, A. (2008). El gobierno corporativo: un enfoque moderno "Un gobierno corporativo pobre introduce factores de riesgo. Un buen gobierno corporativo reduce el riesgo". Revistas de investigación UNMSM , 15(29), 7-22.

Gómez Gutiérrez, C. (2014). El desarrollo sostenible: conceptos básicos, alcance y criterios para su evaluación. En B. Gareda Moreda. (1. Ed). Cambio climático y desarrollo sostenible. Bases conceptuales para la educación en Cuba. (pp. 136). La Habana, Cuba: Educación Cubana.

Herrera Gómez, Á., Lazo Damián, A., Mollo Bustamante, G., y Vera Melgar, M.

Planeamiento estratégico de gestión de residuos en el sector textil peruano.

Recuperado de

https://www.latinburkenroad.com/docs/BRLA\%20Peruvian\%20Textile\%20Indus try\%20(201003).pdf

International Team Consulting. (7 de diciembre del 2015). La Industria del textil en Francia se reinventa: el tejido técnico. Recuperado de http://www.intteam.com/la-industria-del-textil-en-francia-se-reinventa-el-tejido-tecnico/

Lafayette. (12 de julio del 2017). Fibras sintéticas vs naturales: los dos extremos del hilo. Recuperado de https://www.lafayette.com/blog/noticias/fibras-sinteticasnaturales/

Lozano, I. (21 de agosto del 2018). Exportaciones textiles de alpaca crecieron 48,8\% en el primer semestre. Recuperado de https://larepublica.pe/economia/1302063exportaciones-textiles-alpaca-crecieron-488-primer-semestre

Mares, A. (31 de febrero del 2018). China se confirma como el mayor exportador de indumentaria hacia Argentina en 2017. Recuperado de http://pe.fashionnetwork.com/news/China-se-confirma-como-el-mayorexportador-de-indumentaria-hacia-Argentina-en2017,942772.html\#.W6CiCOgza1u 
Medina, M. (2 de julio del 2018). Perú entre los diez primeros proveedores de prendas de vestir en Estados Unidos. Recuperado de https://diariocorreo.pe/economia/peru-entre-los-diez-primeros-proveedores-deprendas-de-vestir-en-estados-unidos-827709/

Olazábal, V. (24 de abril del 2018). Cinco años del derrumbe del Rana Plaza: logros y cuentas pendientes en la industria textil de Bangladesh. Recuperado de http://www.elmundo.es/internacional/2018/04/24/5adf0ca6e2704e18538b461a.ht $\mathrm{ml}$

PerúRetail. (1 de marzo del 2018). El 22\% del total de las importaciones textiles de Bolivia provienen de China. Recuperado de https://www.peru-retail.com/22total-importaciones-textiles-bolivia-provienen-china/

Porter, M. E., y Kramer, M. R. (2011). La creación de valor compartido.

Rosenthal, V. (2002). Comunicación y estrategia. Recuperado de la base de datos de UESAN (042817)

Villaécija, R. (3 de setiembre del 2018). Firmado el convenio del sector textil con un alza salarial del $2 \%$ en 2018 y 2019 . Recuperado de http://www.elmundo.es/economia/empresas/2018/09/03/5b8d348346163f9b398b 4668.html

Xicota, E. (16 de agosto del 2018). Impactos del fast fashion en el desarrollo del Perú. Recuperado de https://www.esterxicota.com/impactos-fast-fashion-peru/ 


\section{ANEXOS}

\section{Entrevista}

Medio: Revista Stakeholders

Entrevistada: Ester Xicota, Co-fundadora de la Asociación de Moda Sostenible del Perú (AMSP)

Tema: Moda Sostenible

¿Cómo ha evolucionado el tema de la Moda Sostenible? ¿Existen avances o casos al respecto? ¿Existen o cuentan con datos al respecto, ya sea nivel internacional como a nivel local?

La Asociación de Moda Sostenible del Perú (AMSP) ha sido solicitada a participar en foros representativos del sector como el Foro Textil Exportador de ADEX, eventos de Promperu e incluso, en eventos internacionales. Adicionalmente, el sector de la moda sostenible es ahora mucho más visible gracias a las acciones de la AMSP y la reciente presentación del 1er Directorio de Moda sostenible, documento que reúne a 75 organizaciones y diseñadores que están innovando en sus procesos de producción.

Decidimos realizar esta investigación porque identificamos la ausencia de información y datos a nivel local sobre el sector de la moda sostenible. Lanzamos la convocatoria a fines del 2015 y las organizaciones y diseñadores se inscribieron a través de un cuestionario virtual. De las 253 empresas que se inscribieron al primer directorio de moda sostenible en el Perú, la AMSP filtró hasta quedarse con 75 organizaciones. De estas, el $65 \%$ eran empresas y el $17 \%$ empresas sociales. El $80 \%$ de las organizaciones radica en Lima.

Posteriormente vino una etapa de validación de información que mostró que las actividades más frecuentes en la cadena de valor de las organizaciones inscritas son diseño (81\%), confección (75\%) y venta al cliente final (83\%). Adicionalmente, más del $50 \%$ se dedican al tejido y/o confección de telas y la producción de accesorios 
también es una actividad frecuente $(60 \%)$. Al analizar los aspectos relacionados a la sostenibilidad de las organizaciones inscritas encontramos que las organizaciones de moda sostenible en Perú producen de manera local (79\%), hacen trabajo artesanal (79 $\%)$, trabajan con materiales naturales $(73 \%)$ y tienen un fuerte componente de inclusión social $(69 \%)$.

En base a estos datos, la AMSP ha confeccionado lo que podríamos llamar el Perfil de la Organización de Moda Sostenible del Perú

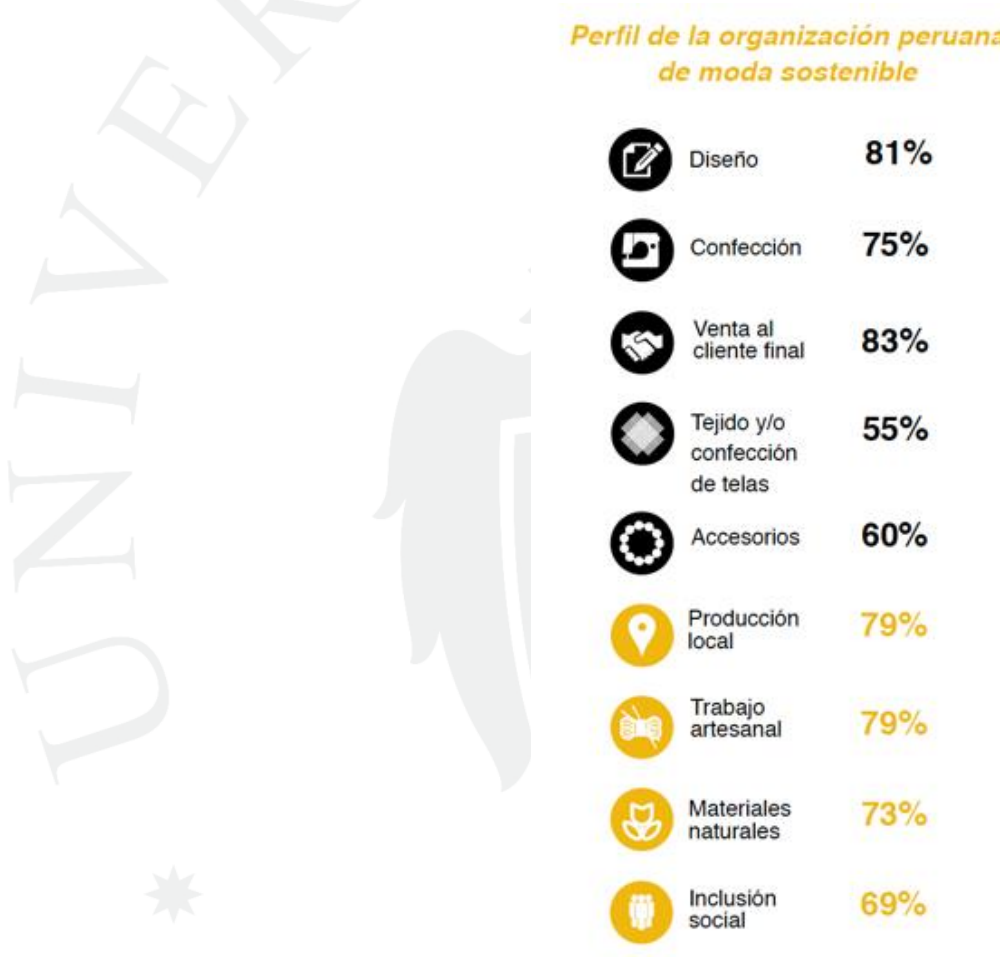

Invitamos a todos los lectores de la revista a descargar Directorio aquí: http://bit.ly/DescargaDirectorio

¿Cómo calificar la problemática que esconde la moda sostenible tanto por el impacto en el medio ambiente como por la explotación de millones de trabajadores de todo el mundo? ¿También se podría considerar en toda la cadena de valor a los proveedores que son claves en la producción y distribución? 
La problemática es muy grave. Se considera a la industria de la moda una de las más contaminantes del mundo. Es altamente intensiva en territorio (cultivo de la materia prima), materiales no renovables y tóxicos (petróleo, químicos y fertilizantes), grandes consumos de agua tanto en el proceso de teñido como acabado de las prendas y un considerable impacto en el cambio climático debido a la necesidad de distribuir los productos a nivel mundial.

Los impactos originan en todos los puntos de la cadena de valor de la industria y al ser esta altamente fragmentada (algunas compañías reportan tener más de 1000 proveedores) y dispersa (una prenda de ropa da más de una vuelta al mundo desde que se inicia la producción de materia prima hasta que está en manos del consumidor) se hace muy difícil controlar dichos impactos.

La gestión de cadena de valor (supply chain management) es esencial en el camino a una moda más sostenible.

En relación a la pregunta anterior, ¿el consumidor peruano es consciente de la implicancia que tiene el modelo Fast Fashion y de los beneficios que tiene, por su parte, el Slow Fashion?

El consumidor peruano, como en general los consumidores de todo el mundo, es ajeno a la magnitud de los impactos que tienen las prendas que compran. El nivel de conciencia aumenta gracias a las acciones de organizaciones nacionales (como la AMSP) e internacionales (como Fashion Revolution) que buscan empoderar al consumidor a través de información, y les dan argumentos para alzar la voz y exigir más transparencia y más cuidado en la producción.

Podemos decir que estamos en los estadios iniciales de toma de conciencia. Por ello es tan esencial la el desarrollo de investigaciones como el Directorio de Moda Sostenible del Perú ya que cuando un consumidor descubre el impacto de sus compras, tiene a mano una herramienta que le proporciona opciones de compra más sostenible. 
Por parte de los productores y confeccionistas, emprendedores entre otros, ¿cuesta tanto elaborar combinaciones de materiales alternativos y sostenibles? ¿Qué tan rentable es meterse al modelo del "Slow Fashion"?

Iniciar el camino a la sostenibilidad no es difícil. Se puede iniciar introduciendo mejores materiales, pero también con procesos más eficientes y avanzados que tienen importantes ahorros de costos, así como en una mejora de las prácticas de gestión de Recursos Humanos.

Lo que es importante hacer notar es que el camino a la sostenibilidad es un proceso de mejora continua y que la sostenibilidad representa un cambio de mentalidad en el sector, y permite mejorar e innovar en todas las áreas de la empresa. Las empresas deben estar preparadas para la mejora constante si quieren implementar la sostenibilidad.

La razón por la cual aún estamos en un estadio incipiente es porque existe una falta de conocimiento por parte de los empresarios textiles tanto de los impactos como de las alternativas. Otra vez, el Directorio aquí tiene un rol primordial a la hora de poner a disposición de los empresarios, alternativas de aprovisionamiento sostenibles e innovadoras.

El modelo slow fashion/moda sostenible es rentable como lo demuestran empresas como Qaytu, Ayni y otras más que están en el Directorio de Moda sostenible. Estas empresas han encontrado nichos de mercado tanto a nivel nacional como internacional, altamente rentables que aprecian los productos social y ambientalmente responsables. Estos nichos están en crecimiento tanto por el alto poder adquisitivo de la generación Boomers como por los nuevos e implicados Millenials.

Resulta evidente la repercusión que ha tenido el Fast Fashion en nuestro país, sin embargo, ¿cómo enfrentar la precariedad laboral y la inequidad (comercio injusto) que existe en los trabajadores textiles?

El modelo de fast fashion es en sí mismo un modelo insostenible por estar basado en un consumo desenfrenado de prendas de baja calidad que contaminan el ambiente y 
obligan a los proveedores a producir con tiempos de entrega y precios imposibles de cumplir siguiendo un modelo de negocio que respete la dignidad humana y los derechos de los trabajadores.

Algunas fast fashion están haciendo esfuerzos por reducir su impacto, mejorar sus productos y procesos pero hasta que no cambie de raíz el modelo de negocio, no podremos hablar de un compromiso serio hacia una moda más sostenible. A la escala de los grandes retailers, implementar la moda sostenible requiere de un cambio de mentalidad y una innovación en el modelo de negocio desde el momento inicial.

\section{¿En qué medida interviene el Estado en este tipo de problemáticas?}

El Estado peruano ha intervenido en diversos frentes. Por un lado, ha venido mejorando la legislación y la fiscalización para las empresas del sector. A pesar que la informalidad es aún alta, las grandes empresas del sector textil cumplen con estándares laborales y ambientales que mejoran progresivamente. Adicionalmente, el gobierno, a través de Promperu y el MINCETUR ha venido trabajando en promover el sector de la moda sostenible en los mercados internacionales.

\section{¿La moda crea productos que refuerzan las desigualdades?}

Definitivamente sí. La moda es un espejo de la sociedad y, aunque la industria de la moda no es responsable de las características de la sociedad en la que opera, sí es una potente fuerza a la hora de promover los valores que imperan en ella.

Por un lado, el modelo de fast fashion requiere que los consumidores compren cada vez más, más rápido y a un precio más bajo. Esto genera una cultura consumista que tiene como consecuencias la infelicidad de las personas, la explotación laboral en todo el mundo y el uso de prácticas industriales que tienen poco cuidado con los insumos y los productos que usan. Lo más rápido posible al menor precio significa niveles muy bajos de calidad humana, ambiental y de producto.

Por otro, las empresas de moda tienen una potente influencia en la percepción de lo deseado y lo exitoso en una sociedad. Crean estilos de vida y apariencias y empujan a los consumidores a seguirlas a través de sus actos de compra. En el Perú, por ejemplo, ya ha habido más de un escándalo social por el tema de la publicidad que usan las marcas. Empresas como Saga o Ripley utilizan modelos blancas y de una apariencia europea/nórdica que busca tener un efecto aspiracional en los consumidores pero que genera claras situaciones de discriminación.

La preocupación es que los niños sigan creciendo con un modelo de persona exitosa que no se parece nada a ellos y quieran ser algo que no son, que no podrán cambiar y que perpetúen este estereotipo pernicioso que eleva a un tipo de persona y degrada a otro.

\section{A raíz del documental, The True Cost es posible hablar de moda sostenible? ¿A costa de qué?}


El documental The True Cost ha marcado un hito a nivel internacional al poner a disposición de los ciudadanos, información simple pero completa y concreta sobre las consecuencias de nuestras compras.

The True Cost, como también el movimiento Fashion Revolution, es una potente herramienta de comunicación y concienciación. Desde la Asociación de Moda Sostenible del Perú, hemos venido difundiendo el documental de manera constante en universidades y escuelas de moda a nivel nacional.

\section{Entrevista}

\section{ENTREVISTA}

- Tema: Moda Sostenible

- Empresa: Asociación de Moda Sostenible del Perú (AMSP)

- Entrevistado: Ornella Paz

- Cargo: Co-Fundadora

\section{GUÍA DE PREGUNTAS}

\section{En el Perú ¿cómo ha evolucionado el tema de la Moda Sostenible? ¿Existen avances o casos al respecto? ¿Existen o cuentan con datos al respecto?}

La moda sostenibe es una tendencia mundial que tiene como finalidad que todos los involucrados de la cadena de valor de la industria textil, desde el productor hasta el consumidor final, tomen conciencia social y ambiental con respecto a sus productos, generando el menor impacto negativo.

En nuestro país, el $39 \%^{3}$ de personas dicen ser leales a una marca, mientras que el $61 \%$ restante está dispuesto a cambiarla, debido a que como no se encuentra la marca adecuada están dispuestos a probar nuevas opciones, y para ello las marcas deben estar preparadas para generar propuestas interesantes que cubran las expectativas de sus

\footnotetext{
${ }^{3}$ Estudio Arellano: http://www.arellanomarketing.com/inicio/arellano-marketing-el-consumidor-peruano-ha-subido-un-peldano/
} 
consumidores y además, le brinden un valor agregado como la sostenibilidad y la innovación, intangibles muy valorados por ellos. No en vano hoy en día exiten rankings, certitifiacaciones y hasta premios que califican a las empresas y marcas por sus indicadores como la confiabilidad, transparencia, responsabilidad social empresarial, innovación, entre otros. Lo cual nos da una idea muy clara de cuál es la demanda.

En este sentido, la decisión de una marca o empresa del sector textil de apostar por la sostenibilidad, implementar procesos limpios en su cadena de valor que contribuyan al cuidado del medio ambiente, reducir el uso de agua y de productos químicos en sus diferentes procesos, brindar salario justo, no ejercer el uso de la mano de obra infantil, respetar por los derechos laborales y humanos, generar comercio justo, entre otros aspectos, definitivamente lo diferenciará del resto de marcas comerciales.

En la AMSP estamos totalmente convencidos que posicionar la moda sostenible en nuestro país, no solo es responsabilidad de las marcas o empresas, sino de todos los que nos involucramos en el sector. Desde el momento en que compraste una prenda de vestir, ya eres responsable de lo que está sucediendo en este ámbito. El consumidor final es uno de los actores más importantes, porque es quien decide si mantiene en el mercado a una marca o no. Asimismo tenemos mucho interés de dirigirnos a la academia, por dos razones: los alumnos de las carreras de diseño de moda y afines, que están en plena formación, son quienes deben informarse que al finalizar sus estudios y cuando emprendan un negocio en este rubro, tienen una opción sostenible que logrará impactar de manera positiva no solo en sus clientes sino a un mayor número de stakeholders.

Asimismo, el área de investigación de la academia nos interesa mucho para poder crear nexos y realizar un diagnóstico de lo que está sucediendo en el sector textil de nuestro país. ¿Respetamos horarios laborales? ¿Se paga un sueldo justo? ¿Utilizamos manos de obra infantil? ¿En qué condiciones trabajan las personas del sector textil? Todas ellas son interrogantes que queremos responder y solo será posible a través de la investigación y estudios que la AMSP junto a diversas instituciones está dispuesta a desarrollar. 
2. ¿Cómo calificar la problemática que esconde la moda sostenible tanto por el impacto en el medio ambiente como por la explotación de millones de trabajadores de todo el mundo? ¿En el Perú se ha vivido alguna situación similar al caso Bangladés?

Se estima que para la creación de una camiseta de algodón de 250 gr de algodón se utiliza cerca de 2,900 $\operatorname{litros}^{4}$ de agua (desde la producción de la materia prima hasta que llega a las manos del consumidor).

Quizá podemos pensar que es una realidad muy lejana y difícil de que suceda en nuestro país. La verdad es que si aún no te has puesto a pensar de dónde viene tu ropa, es momento de hacerlo, porque quizá muchas de las prendas que tienes tengan detrás una historia que contar con el de las mujeres de Camboya que son explotadas.

En el Perú no hemos tenido una situación similar al peor accidente de la historia del sector moda/textil, me refiero al colapso del edificio Rana Plaza en Bangladesh. Este accidente sucedió en abril 2013, después de que varias ONGs advirtieran a los dueños de dicho edificio de que era un espacio inhabitable y las personas trabajaban en malísimas condiciones. Finalmente, el edificio colapso matando a más de 2000 personas (en su mayoría mujeres y niños) y dejó herido a más de 1000 personas.

Este accidente no hubiera sido tan mediático, si no fuera porque 5 marcas grandes de marca y ropa realizaban sus producciones en ese edificio. La pregunta es: ¿cuál es el compromiso de dichas marcas con sus proveedores? ¿Realmente existe?

3. Resulta evidente la repercusión que ha tenido el Fast Fashion en nuestro país, sin embargo, ¿cómo enfrentar la precariedad laboral y la inequidad que existe en los trabajadores textiles?

La mejor arma para enfrentar la precariedad laboral y la inequidad que existe en los trabajadores textiles es educando y creando conciencia en el consumidor final. La

4 Dutchman Arjen Hoekstra, the father of the water footprint concept 
Asociación tiene 3 objetivos: articular, visibilizar y fortalecer iniciativas de moda sostenible en nuestro país.

Deseamos que las personas pregunten a las marcas: ¿quién hace mi ropa?, que cuestionen la razón de los bajos precios. Y en base a ello decidan una compra consciente. Si tenemos un comprador informado, exigirá una prenda de calidad, y estará dispuesto a pagar el precio. Ahí entra el trabajo de la AMSP, informar y concientizar al respecto.

\section{4. ¿La moda crea productos que refuerzan las desigualdades?}

El fast fashion en su afán de renovarse constantemente como su propio nombre lo dice puede crear productos que refuercen desigualdades en los consumidores.

El modelo de negocio de la moda sostenible esta preocupada en estimular el uso de recursos naturales de manera responsable y eficiente, asimismo busca el respeto con el entorno (personas, ambiente, empresas). Nosotros los peruanos somos privilegiados al tener en nuestras fibras naturales el algodón pima, tanguis, la fina fibra de vicuña y alpaca, de contar con mano de obra local con experiencia, sin animo de explotar a los trabajadores, tener planes para crear conciencia de protección al ambiente sin generar residuos.

La moda sostenible plantea un cambio y este cambio conseguirá una transformación en la cadena de producción hasta llegar al consumidor final.

En relación a lo anterior, ¿a qué sector (público o privado) corresponde enfrentar dicha problemática? ¿De qué manera?

Esta problemática lo debe enfrentar el sector público tanto como el sector privado.

Trabajar en equipo para dar a conocer a los empresarios textiles las ventajas de los procesos de produccion eficientes, con responsabilidad en nuestro entorno.

5. A raíz del documental, The True Cost es posible hablar de moda sostenible? ¿A costa de qué? 
El documental The True Cost del director Andrew Morgan nos muestra el lado oculto del fast fashion, enseña a los consumidores el mal uso de los recursos naturales, la explotación laboral, las malas condiciones de trabajo en Bangladesh y Camboya. Las grandes empresas negocian el precio más bajo con los productores, y como los productores no tienen más opciones, aceptan propuestas injustas.

La moda sostenible es un modelo de negocio que funciona, existen casos de ello, entonces si es posible hacer moda sostenible y la Asociacion de Moda Sostenible del Perú ha nacido para impulsar y dar a conocer a toda la sociedad, las iniciativas que están en esta dirección o tienen interés en orientarse hacia la sostenibilidad.

Creemos que en nuestro país falta desarrollar una culltura de compromiso y responsabilidad, que nos lleve a preguntarnos, antes de tomar una decision de compra: ¿de dónde y en qué condiciones provienen las prendas que compro? Y exigir a las marcas a que hagan pública dicha información, como práctica de transparencia y compromiso con ellos mismos. La moda sostenible justamente se basa en estos 2 aspectos fundamentales: respeto por los demás y el consumo responsable.

Hace falta un poco de sensibilidad, no solo en los consumidores sino también en las marcas de moda peruana o empresas de este sector y medios de comunicación. Creemos que si del mismo modo que en nuestro día a día tenemos la obligación moral de dar el ejemplo a otras personas para que se comporten con buena voluntad, también las empresas y marcas se deberían fijar metas para concienciar a las personas y a sus propios pares.

\section{Entrevista}

\section{CUESTIONARIO}

- Tema: ¿Cómo lograr una cadena de suministro eficaz y responsable en el rubro textil?

- Empresa: ESAN

- Entrevistado: Pool Rousell Ccanto Palacios

- Cargo: Profesor de la Maestría en Supply Chain Management de la Universidad ESAN 


\section{GUÍA DE PREGUNTAS}

1. ¿Qué significa tener una cadena de suministro eficaz y responsable en el rubro textil?

Significa responder a la demanda de los consumidores en coordinando un adecuado flujo de materiales que va desde los proveedores de materias primas e insumos hasta que las prendas lleguen a las manos de los consumidores. Y que en todas las fases de la cadena de suministro sean amigables con el medio ambiente que los rodea y que todos los involucrados también lo sean para hacerlo sostenible en el largo plazo.

2. ¿De qué manera se reconoce el papel que juega el trabajador textil dentro de la cadena de suministro?

El trabajador textil es el responsable del proceso productivo que va desde el diseño de la prenda hasta la distribución y él es el encargado de elegir que materiales utilizar, elegir a sus proveedores y realizar los cortes para que pueda fabricar una prenda que satisfaga la necesidad de los consumidores.

3. ¿Considera que las empresas del rubro textil prefieren calidad o mano de obra barata? ¿Por qué?

En si todo depende del segmento del mercado puesto que si el fabricante textil está enfocado en segmentos A y B prefieren la calidad ya que dicho mercado está dispuesto a pagar más por una prenda, es aquí donde también se considera el valor de la "Marca Global", por otro lado si es una empresa textil está enfocada en segmentos C, D o E ellos priorizarán reducir costos y dentro de ello la mano de obra barata, ya que en dichos segmentos la variable precio es la que manda.

4. ¿Cuáles son los principales problemas que enfrenta el sector textil actualmente dentro de la cadena de suministro?

El problema principal es la informalidad con la que trabajan de las empresas que participan en la cadena, esto va desde los agricultores del algodón hasta 
los puntos de venta. Considero que se deben desarrollar y tecnificar las empresas textiles con el fin de diseñar prendas y mejorar crear tendencias de moda de clase mundial, para ello hay que estar a la vanguardia de las necesidades de los clientes. Considero además que debemos explotar la ventaja comparativa que tenemos que el Algodón 100 \% Pima Peruano es reconocido en el mundo entero y pocas empresas son las que desarrollan esta ventaja.

Otro de los problemas es la mano de obra calificada, ya que únicamente se busca obreros que hagan los procesos de corte, costura o pegado de botones, pero se invierte poco en creación de diseños o generar tendencias.

Finalmente, otro problema es que las empresas textiles peruanas no están logrando competitividad, y esto se ve traducido en los costos de producción es por ello que como país hemos sido desplazados por países Centroamericanos (Nicaragua, El Salvador y Honduras), ya que ellos manejan entre costos de producción en el orden de US\$2.16 hasta US\$2.80 mientras que el empresario textil peruano tiene un costo promedio de US\$ 6.18.

\section{5. ¿Qué están haciendo las empresas para enfrentar esta situación?}

Realmente no se tiene vistos de mejoría, inclusive dada esta coyuntura, aunque no se han pronunciado aún, algunos de las principales empresas textiles están barajando la posibilidad de mover su producción a mercados Centroamericanos puesto que los costos laborales (uno de los principales) son más económicos y al estar en zonas francas tienen aún mayores beneficios.

6. ¿De qué manera una adecuada gestión de la cadena de suministro podría contribuir a que la empresa controle los riesgos vinculados a su reputación corporativa?

Una buena cadena de suministro en el sector textil generaría competitividad a las empresas, los costos se reducirían, se mejoraría la calidad de los productos, daría mejor imagen a la empresa, puesto que cumpliría con altos 
niveles de servicio y los clientes estarían satisfechos con el desempeño de las empresas. Esa sería la clave para el repunte del sector textil. 